\title{
Neutralization of Nogo-A Enhances Synaptic Plasticity in the Rodent Motor Cortex and Improves Motor Learning in Vivo
}

\author{
(D)Ajmal Zemmar, ${ }^{1,2}$ Oliver Weinmann, ${ }^{1,2}$ Yves Kellner, ${ }^{3}$ Xinzhu Yu, ${ }^{4}$ Raul Vicente, ${ }^{5}$ Miriam Gullo, ${ }^{1,2}$ Hansjörg Kasper, ${ }^{1}$ \\ Karin Lussi, ${ }^{1}$ Zorica Ristic, ${ }^{1,2}$ Andreas R. Luft, ${ }^{6}$ Mengia Rioult-Pedotti, ${ }^{6}$ Yi Zuo, ${ }_{4}^{4}$ Marta Zagrebelsky, ${ }^{3}$ and Martin E. Schwab ${ }^{1,2}$ \\ ${ }^{1}$ Brain Research Institute, University of Zurich, 8057 Zurich, Switzerland, ${ }^{2}$ Department of Health Sciences and Technology, ETH Zurich, 8057 Zurich, \\ Switzerland, ${ }^{3}$ Division of Cellular Neurobiology, Zoological Institute, Technische Universität Braunschweig, 38106 Braunschweig, Germany, ${ }^{4}$ Department of \\ Molecular, Cell, and Developmental Biology, University of California, Santa Cruz, California 95064, ${ }^{5}$ Department of Neurophysiology, Max Planck Institute \\ for Brain Research, 60528 Frankfurt, Germany, and ${ }^{6}$ Clinical Neurorehabilitation, Department of Neurology, University and University Hospital, Zurich, \\ 8008 Zurich, Switzerland
}

The membrane protein Nogo-A is known as an inhibitor of axonal outgrowth and regeneration in the CNS. However, its physiological functions in the normal adult CNS remain incompletely understood. Here, we investigated the role of Nogo-A in cortical synaptic plasticity and motor learning in the uninjured adult rodent motor cortex. Nogo-A and its receptor NgR1 are present at cortical synapses. Acute treatment of slices with function-blocking antibodies (Abs) against Nogo-A or against NgR1 increased long-term potentiation (LTP) induced by stimulation of layer 2/3 horizontal fibers. Furthermore, anti-Nogo-A Ab treatment increased LTP saturation levels, whereas long-term depression remained unchanged, thus leading to an enlarged synaptic modification range. In vivo, intrathecal application of Nogo-A-blocking Abs resulted in a higher dendritic spine density at cortical pyramidal neurons due to an increase in spine formation as revealed by in vivo two-photon microscopy. To investigate whether these changes in synaptic plasticity correlate with motor learning, we trained rats to learn a skilled forelimb-reaching task while receiving anti-Nogo-A Abs. Learning of this cortically controlled precision movement was improved upon anti-Nogo-A Ab treatment. Our results identify Nogo-A as an influential molecular modulator of synaptic plasticity and as a regulator for learning of skilled movements in the motor cortex.

Key words: two-photon; in vivo; LTP; motor learning; Nogo-A; synaptic plasticity

\section{Introduction}

Activity-driven long lasting changes in the efficacy of synaptic transmission can be expressed as long-term potentiation (LTP) or long-term depression (LTD) and can correlate with structural modifications, for example, at dendritic spines (Yu and Zuo, 2011). Both, functional and structural synaptic plasticity have been shown to serve as underlying mechanisms for learning and memory in several regions of the brain (Marr, 1969; Morris et al., 1986; Ito, 2001; Kandel, 2001; Whitlock et al., 2006; Holtmaat and Svoboda, 2009; Yang et al., 2009), including acquisition of

Received Sept. 5, 2013; revised May 6, 2014; accepted May 8, 2014.

Author contributions: A.Z., Y.Z., M.Z., and M.E.S. designed research; A.Z., O.W., Y.K., X.Y., M.G., K.L., Z.R., M.R.-P., Y.Z., and M.Z. performed research; A.Z., H.K., A.R.L., and M.E.S. contributed unpublished reagents/analytic tools; A.Z., O.W., Y.K., X.Y., R.V., H.K., K.L., M.R.-P., Y.Z., and M.Z. analyzed data; A.Z. and M.E.S. wrote the paper.

This work was supported by the Swiss National Science Foundation (Grant31003A-149315-1 to M.E.S. and Grant IZK0Z3-150809 to A.Z.), the European Research Council (Advanced Grant to M.E.S.), the Christopher and Dana Reeve Foundation Spinal Cord Consortium, the German Science Foundation (Grant ZA 554/2-1 to M.Z. and Y.K.), and the National Institute of Mental Health-National Institutes of Health (Y.Z.). We thank Beat Gähwiler and Heinz Welzl for critical comments on this manuscript; Wolf Singer, Kevan Martin, and Roland Krüppel for fruitful remarks; Johannes Bohacek and Isabelle Mansuy for infrastructural support; Benjamin Ineichen, Dubravka Göckeritz-Dujmovic, Regula Schneider, Lisa Schnell, and Clement Atiemo for technical support; and Sam Klambour for excellent IT support.

The authors declare no competing financial interests.

Correspondence should be addressed to Ajmal Zemmar, Brain Research Institute, University of Zurich, Winterthurerstrasse 190, 8057 Zurich, Switzerland. E-mail: zemmar@hifo.uzh.ch.

M. Schwab's present address: Brain Research Institute, University of Zurich, 8057 Zurich, Switzerland.

DOI:10.1523/JNEUROSCI.3817-13.2014

Copyright $\odot 2014$ the authors $\quad 0270-6474 / 14 / 348685-14 \$ 15.00 / 0$ novel motor skills (Rioult-Pedotti et al., 1998; Rioult-Pedotti et al., 2000; Harms et al., 2008; Xu et al., 2009; Fu et al., 2012; but also see Cohen and Castro-Alamancos 2005; Welsh et al., 2005; Llinás, 2011).

The membrane protein Nogo-A was originally identified as a myelin-associated neurite outgrowth inhibitor in the adult CNS (Caroni and Schwab, 1988; Chen et al., 2000). Neutralization of Nogo-A, of its receptor NgR1, or inhibition of the downstream signaling cascades via Rho-A and Rho-associated protein kinase (ROCK) enhance regenerative and compensatory fiber growth and improve functional recovery after CNS injury or stroke (Schnell and Schwab, 1990; Chen et al., 2000; GrandPré et al., 2002; Fournier et al., 2003; Kim et al., 2004; Liebscher et al., 2005; Gonzenbach and Schwab, 2008; Schwab, 2010; Akbik et al., 2012). In addition to its source in oligodendrocytes, Nogo-A is expressed by subtypes of neurons, especially in plastic areas such as the hippocampus, neocortex, and the subventricular zone/olfactory bulb system (Huber et al., 2002; Wang et al., 2002; Grunwald et al., 2004; Raiker et al., 2010; Rolando et al., 2012). In the hippocampus, neuronal Nogo-A and its receptor, NgR1, negatively modulate functional synaptic plasticity (Lee et al., 2008; Raiker et al., 2010; Delekate et al., 2011).

Structurally, neutralization or ablation of Nogo-A or NgR1 increase axonal growth, modulate dendritic branching, and enhance spine turnover rate and density (Craveiro et al., 2008; 
Table 1. Relative labeling index (RLI) of HRP-DAB gold product in M1 layer 2/3

\begin{tabular}{|c|c|c|c|c|c|c|}
\hline & $\begin{array}{l}\text { Immunoreactive } \\
\text { compartments }\end{array}$ & $\begin{array}{l}\text { Total } \\
\text { compartments }\end{array}$ & $\begin{array}{l}\text { Expected random } \\
\text { labeling }\end{array}$ & RLI & $\chi^{2}$ & $\begin{array}{l}\text { Percentage of immunoreactive } \\
\text { compartments }\end{array}$ \\
\hline \multicolumn{7}{|l|}{ vGlut1 } \\
\hline Dendrites & 2 & 158 & 33.9 & 0.1 & 30.0 & $1.3 \%$ \\
\hline Spines & 0 & 36 & 7.7 & 0.0 & 7.7 & $0 \%$ \\
\hline Presynaptic terminal & 83 & 96 & 20.6 & 4 & $189 * * *$ & $86.5 \%$ \\
\hline Axons & 14 & 52 & 11.2 & 1.3 & 0.7 & $26.9 \%$ \\
\hline Glia, extracellular space & 4 & 138 & 29.6 & 0.1 & 22.2 & $2.9 \%$ \\
\hline Total & 103 & 480 & 103.0 & 5.5 & 249.6 & \\
\hline \multicolumn{7}{|l|}{ Nogo-A } \\
\hline Dendrites & 184 & 197 & 42.3 & 4.4 & $475.2^{* * *}$ & $93.4 \%$ \\
\hline Spines & 24 & 37 & 7.9 & 3.0 & $32.5^{* * *}$ & $64.9 \%$ \\
\hline Presynaptic terminal & 25 & 72 & 15.5 & 1.6 & 5.9 & $34.7 \%$ \\
\hline Axons & 8 & 47 & 10.1 & 0.8 & 0.4 & $17.0 \%$ \\
\hline Glia, extracellular space & 3 & 127 & 27.3 & 0.1 & 21.6 & $2.4 \%$ \\
\hline Total & 244 & 480 & 103.0 & 9.9 & 535.6 & \\
\hline \multicolumn{7}{|l|}{$\mathrm{NgR1}$} \\
\hline Dendrites & 24 & 174 & 37.3 & 0.6 & 4.8 & $13.8 \%$ \\
\hline Spines & 7 & 31 & 6.7 & 1.1 & 0 & $22.6 \%$ \\
\hline Presynaptic terminal & 98 & 101 & 21.7 & 4.5 & $268.8^{* * *}$ & $97.0 \%$ \\
\hline Axons & 14 & 32 & 6.9 & 2.0 & 7.4 & $43.8 \%$ \\
\hline Glia, extracellular space & 2 & 142 & 30.5 & 0.1 & 26.6 & $1.4 \%$ \\
\hline Total & 145 & 480 & 103.0 & 8.3 & 307.6 & \\
\hline
\end{tabular}

For a total $\chi^{2}$ of 249 and 4 degrees of freedom ( $2-1$ groups $\times 5-1$ compartments). Significant labeling is observed in the presynaptic terminal ( $p<0.0001 ; \chi^{2}$ test). The distribution of HRP DAB-gold product is not random and the bold values of RLI show the preferential labeling of compartments $(R L I>1)$.

*** $p<0.001$.

Schwab, 2010; Zagrebelsky et al., 2010; Wills et al., 2012; Akbik et al., 2013). In the visual and the somatosensory cortex, genetic ablation of Nogo-A/B, of NgR1, or of the Nogo-binding partner Paired Ig-like Receptor B (PirB) prolong plasticity of ocular dominance columns far into adult age in mice (McGee et al., 2005; Syken et al., 2006; Akbik et al., 2013). Together, these studies reveal a role for Nogo signaling in remodeling of synaptic strength and structure (Akbik et al., 2012; Mironova and Giger, 2013). Whether Nogo-A impacts cortically controlled learning is currently unknown.

Here, we investigated the influence of Nogo-A signaling on functional and structural synaptic plasticity in the motor cortex of adult rats and mice and during motor learning in vivo. At an ultrastructural level, we confirmed the presence of Nogo-A and $\mathrm{NgR} 1$ at synaptic sites of the motor cortex. Functional neutralization of Nogo-A or of NgR1 by Abs increased electrically induced synaptic strength (LTP) within minutes and spine density of pyramidal neurons in vivo within days. Motor learning of a skilled forelimb-reaching task in rats was improved upon antiNogo-A Ab treatment. Our results identify Nogo-A as an influential molecular modulator of synaptic plasticity and learning in the motor cortex.

\section{Materials and Methods}

Animals. Adult male Sprague Dawley rats (5-6 weeks, 190-220 g; Janvier) were used for LTP, LTD, in vivo motor learning, and electron microscopy experiments. Rats were housed in standard cages in groups of three animals per cage in a reversed light/dark cycle (light on 8:00 P.M., light off 8:00 A.M.). All experiments were conducted with the approval of the Veterinarian Office Zurich, Switzerland, and in accordance with their guidelines. Thy1-YFP-H line mice (Feng et al., 2000) were purchased from Jackson Laboratory for in vivo imaging of dendritic spines (Table 2). Mice were housed and bred in University of California-Santa Cruz animal facilities according to approved animal protocols.

Localization of Nogo-A and NgR1 in the motor cortex. Animals were deeply anesthetized with Nembutal and fixed by perfusion through the heart with $4 \%$ buffered PFA. Brains were dissected, postfixed overnight at $4^{\circ} \mathrm{C}$, cryoprotected in $30 \%$ sucrose, and sectioned at $40 \mu \mathrm{m}$ in a cryo- stat. The sections were stored in antifreeze solution containing glucose and ethylene glycol (Willi et al., 2010). For all staining, free-floating coronal sections were used. For Nogo-A identification in the motor cortex, immunoperoxidase staining was used with a rabbit primary antiNogo-A antiserum ("Laura," diluted 1:250; Oertle et al., 2003) diluted in $4 \%$ normal goat serum in phosphate buffer (PB) $0.1 \mathrm{M}, \mathrm{pH} 7.4$, with $0.05 \%$ Triton X-100. The sections were then rinsed with buffer, incubated with a biotinylated secondary anti-rabbit Ab (1:300; Jackson ImmunoResearch), and processed for avidin-peroxidase staining (Vectastain Elite Kits; Vector Laboratories) with diaminobenzidine hydrochloride (Sigma-Aldrich) as the chromogen. For NgR1 detection and double staining for synaptophysin, immunofluorescence with following primary Abs was used: mouse monoclonal anti-Nogo-A Ab 11C7 (1 $\mu \mathrm{g} / \mathrm{ml}$; Oertle et al., 2003), goat anti-NgR (1:100; R\&D Systems), rabbit anti-synaptophysin (1:500; Synaptic Systems), and fluorescent deep red Nissl stain NeuroTrace 640/660 (1:200; Invitrogen). The secondary Abs were raised in donkey coupled to indocarbocyanine $\mathrm{Cy} 3$ or to Alexa Fluor 488. After final washing steps in PB, sections were mounted and coverslipped with Mowiol (Calbiochem). Epifluorescence was analyzed in a sequential image acquisition mode by confocal microscopy (TCS SP2; Leica) using $20 \times$ or $100 \times$ objectives.

Immunoelectron microscopy. We used a pre-embedding immunolocalization technique because Nogo-A, like many antigens, can be detected only very weakly after dehydration, osmium fixation, and Epon-Araldite embedding. To detect Nogo-A and NgR1 in the motor cortex, we used the DAB-Ag-Au substitution method (Petrinovic et al., 2013). The resulting DAB-Ag product was stabilized with gold chloride. The disadvantage of this method is the known unspecific staining of myelin by the gold chloride (Schmued, 1990; Schmued et al., 2008). The sparse myelin structures in the cortical layer $2 / 3$, which are known to be Nogo-Apositive (Huber et al., 2002), were therefore excluded from the present analysis.

For pre-embedding immunolocalization of vGlut-1, Nogo-A, and $\mathrm{NgR} 1,40-\mu \mathrm{m}$-thick coronal cryostat sections were prepared from M1 layer $2 / 3$, treated with $0.5 \% \mathrm{NaBH}_{4}$ in Tris-buffered saline (TBS) for 10 min and in $50 \mathrm{~mm}$ Tris glycine, $\mathrm{pH} 8.0$, for $30 \mathrm{~min}$ to quench the free aldehyde groups. After freeze and thaw cycles to enhance the permeability, sections were rinsed several times in TBS and incubated for $2 \mathrm{~d}$ with the primary $\mathrm{Ab}$ (vGlut1, 1:500; Nogo-A/Laura, 1:200; NgR1, 1:100) at $4^{\circ} \mathrm{C}$ on a shaker. Exposition to biotinylated secondary $\mathrm{Ab}$ (1:200; Jackson 
ImmunoResearch) was followed by Streptavidin Peroxidase ABC Elite Kit (1:100; Vector Laboratories). Sections were subsequently incubated with $0.025 \% 3,3^{\prime}$-diaminobenzidine tetrahydrochloride (DAB) in the presence of $0.006 \% \mathrm{H}_{2} \mathrm{O}_{2}$ for $5-10 \mathrm{~min}$. DAB staining was intensified by the methenamine silver-gold reaction as described previously (Fritschy et al., 1999; Petrinovic et al., 2013). Sections were osmicated and, after uranyl acetate contrast incubation, embedded in epoxy. Ultrathin sections of $100 \mathrm{~nm}$ were analyzed in a Zeiss EM10 electron microscope. For quantification of DAB-gold particles, electron microscopic images were randomly obtained from motor cortex layer $2 / 3$ of three Sprague Dawley rats. The number of DAB-gold-positive compartments was divided by the total number of counted compartments $(n=480)$ per antigen.

For synaptic distribution and quantity of Nogo-A, NgR1, and vGlut-1, 30 micrographs from the motor cortex $2 / 3$ of three animals were randomly acquired at $63,000 \times$ on a transmission electron microscope (Zeiss). The volume densities of DAB-gold-positive substructures in five compartments were determined stereologically by overlaying point grid matrix (ImageJ plugin) to count and calculate the relative labeling index and $\chi^{2}$ square $p$-values of DAB-gold-positive compartments (Table 1).

Abs for ex vivo slice physiology experiments. Four different highly purified mouse and goat Abs were used: (1) a monoclonal, Nogo-A specific, function-blocking $\mathrm{Ab}$ raised against an 18 aa peptide in the most active region of Nogo-A (Ab 11C7 (Oertle et al., 2003; Liebscher et al., 2005; Maier et al., 2009; gift from Novartis Pharma); (2) a control mouse IgG $\mathrm{Ab}$ (AbD Serotec), (3) an Ab against the Nogo receptor subunit NgR1 (mNogo receptor affinity-purified goat IgG; lot \#INQ02; R\&D Systems), which was shown effective in hippocampal slice recordings (Delekate et al., 2011); and (4) a goat IgG control Ab (R\&D Systems). Ab solutions were freshly prepared in carbogenated artificial CSF (ACSF) at a final concentration of $5 \mu \mathrm{g} / \mathrm{ml}$. To prevent sticking of the $\mathrm{Ab}$ to the tubing and the chamber, silicon tubing was used and washed with ACSF containing BSA $(0.1 \mathrm{mg} / \mathrm{ml})$. The slices were preincubated for at least 1 hour with the anti-Nogo-A, anti-NgR1, or the respective control Abs in an incubation chamber maintaining a constant flow of the solution. The Nogo-66 antagonist peptide Nep1-40 (N7161; Sigma-Aldrich) was dissolved in distilled water according to the manufacturer's instructions and used at a final concentration of $300 \mathrm{~nm}$ in ACSF. For in vivo experiments, the Nogo-A-specific blocking $\mathrm{Ab}$ and mouse IgG control Ab were used at a concentration of $3.0-4.2 \mathrm{mg} / \mathrm{ml}$ in PBS.

Slice preparation. Coronal slices containing the forelimb area of M1 at 1-2 mm anterior to bregma (Donoghue and Wise, 1982) were prepared from adult Sprague Dawley rats (180-220 g body weight) as described previously (Hess and Donoghue, 1996; Rioult-Pedotti et al., 1998). Animals were anesthetized by intraperitoneal injection of pentobarbital. After decapitation, the brain was removed quickly and coronal slices, $\sim 500$ $\mu \mathrm{m}$ thick, were cut using a vibratome (Leica Biosystems). Identical conditions were used to detect propidium iodide (PI)-positive cells. Slices were incubated with PI $(2.5 \mu \mathrm{g} / \mathrm{ml})$ for $60 \mathrm{~min}$, washed in ACSF, fixed in $4 \%$ PFA, and cryoprotected in $30 \%$ sucrose. Cross-sections of the slices were cut in a cryostat, mounted, and analyzed under a confocal microscope.

Electrophysiological recordings. Slices were stimulated using concentric bipolar microelectrodes (FHC) placed $\sim 2-4 \mathrm{~mm}$ lateral to the midline and $\sim 250-400 \mathrm{pm}$ below the pial surface. Field potentials (FPs) were recorded using glass micropipettes placed $\sim 500 \mu \mathrm{m}$ lateral to the stimulating electrodes. To allow optimal $\mathrm{Ab}$ penetration, we recorded responses from the surface of layer $2 / 3$ within M1. Protocols for inputoutput (IO) analysis, baseline stimulation intensity, and LTP induction were as described previously (Rioult-Pedotti et al., 1998; Rioult-Pedotti et al., 2000). The theta-burst stimulation protocol for LTP induction was induced until responses were saturated. Pathways were considered saturated if the difference between two subsequent states of LTP was not significantly different (Rioult-Pedotti et al., 2000). Saturated LTP was calculated as a percentage of baseline. LTD was attempted by lowfrequency stimulation (LFS; $2 \mathrm{~Hz}$ for $15 \mathrm{~min}$ at double baseline stimulation intensity). LFS was induced for four times (referred to as maximum LTD). Maximum LTD values were computed as percentages of baseline. In contrast to measuring the slope of the FP, as done in most hippocampal recordings, we used the FP amplitude because it serves as a measure of the population excitatory synaptic response (Rioult-Pedotti et al., 1998), reflects a monosynaptic current sink (Hess et al., 1996), and correlates well with the intracellular excitatory postsynaptic response evoked in this pathway (Aroniadou and Keller, 1995).

Presynaptic properties were investigated through paired-pulse measurements, which were performed by applying a pair of two stimuli in different interstimulus intervals in a range of 10,20,40, 80, and $160 \mathrm{~ms}$. The amplitude of the second response was divided by the amplitude of the first response. The result was expressed as the paired-pulse ratio.

Data analysis electrophysiology. Experimental data were collected with LabView software (National Instruments) and analyzed with LabView, MATLAB (MathWorks), Prism (GraphPad), and Excel (Microsoft) software. Horizontal fibers in layer $2 / 3$ of the motor cortex were stimulated and the amplitude of elicited fEPSPs was measured over time, normalized to baseline values, and plotted as average \pm SEM.

Analysis of kinetics. The kinetics of the field response were characterized by rise time and decay time. The rise time was estimated from the $30 / 70$ time (the time it takes the signal to transition from $30 \%$ to $70 \%$ of its maximal value or peak amplitude). Decay time constants were estimated by fitting the decaying phase of the field to a sum of two or three decaying exponentials (Levenberg-Marquardt nonlinear least squares). Decay time reported in the results section refers to the fastest decay time constant obtained by the fitting. The onset of the field response was further characterized by its onset latency and time to peak. The onset latency was obtained as the time interval between the stimulation and response onsets. The time to peak was determined as the time interval between stimulation onset and the field response maximum. All time constants were obtained individually for a total of 1148 trials corresponding to $n=16$ slices (eight treated with anti-Nogo and eight controls). For each slice, the median across trials was computed to reduce the effects of outliers. Each group was finally described by the mean of the individual medians.

Penetration of monoclonal anti-Nogo-A Abs into acute brain slices. Acute slices $(500 \mu \mathrm{m})$ of the forebrain of adult rats, incubated in mouse anti-Nogo-A Ab $11 \mathrm{C} 7(5 \mu \mathrm{g} / \mathrm{ml})$ for $1 \mathrm{~h}$, as prepared for electrophysiology (see Electrophysiological recordings), were subsequently fixed in phosphate-buffered $4 \%$ PFA. After washing, the slices were transferred to $30 \%$ sucrose in PB, flat embedded in Tissue-Tek, and $40 \mu \mathrm{m}$ sections were cut in the perpendicular on a cryostat. These sections were then incubated with a Cy3-conjugated goat anti-mouse IgG Fc $\gamma$ subclass 1-specific Ab (1:200; Jackson ImmunoResearch). The distribution of the anti-Nogo-A mouse IgGs within the tissue was imaged with an Axioplan microscope (Zeiss) equipped with a MCID software module or a Leica Confocal Microscope TCS SP2.

Intrathecal catheter implantation and pump insertion. Animals were anesthetized with a subcutaneous injection of Hypnorm $(600 \mu \mathrm{l} / \mathrm{kg}$ body weight; VetPharm) and Dormicum (750 $\mu \mathrm{l} / \mathrm{kg}$ body weight; Roche Pharmaceuticals). After partial laminectomy at the T3 vertebral level, a fine intrathecal catheter (32 Ga; Recathco) was inserted into the subarachnoid space from the lumbar level L2/L3 and pushed rostrally to the spinal segment C7, delivering the Abs from an osmotic minipump (10 $\mu \mathrm{l} / \mathrm{h}$, 2ML1; Alzet Osmotic Pumps) into the CSF. Abs were continuously delivered into the CSF for $7 \mathrm{~d}$ as described previously (Weinmann et al., 2006; Willi et al., 2010). Sham animals received all surgical steps except for catheter implantation and pump insertion.

In vivo transcranial imaging and data quantification. YFP-H line mice (Feng et al., 2000) of both sexes at 1 month of age were used in all experiments. The surgical procedure for transcranial two-photon imaging of the forelimb motor cortex and data quantification have been described previously (Xu et al., 2009). Intrathecal catheters and pumps for $\mathrm{Ab}$ application were implanted as described in the paragraph "Intrathecal catheter implantation and pump insertion" immediately after the first imaging session. The second time images were obtained $6 \mathrm{~d}$ later. Percentages of eliminated and formed spines were normalized to total spines counted in the first images. Thinned-skull preparation was used in this study. Briefly, mice at 1 month of age were anesthetized with an intraperitoneal injection $(5.0 \mathrm{ml} / \mathrm{kg}$ body weight $)$ of $17 \mathrm{mg} / \mathrm{ml} \mathrm{ketamine} \mathrm{and}$ $1.7 \mathrm{mg} / \mathrm{ml}$ xylazine in $0.9 \% \mathrm{NaCl}$. The skull was exposed with a midline scalp incision and imaged regions were located based on stereotactic 

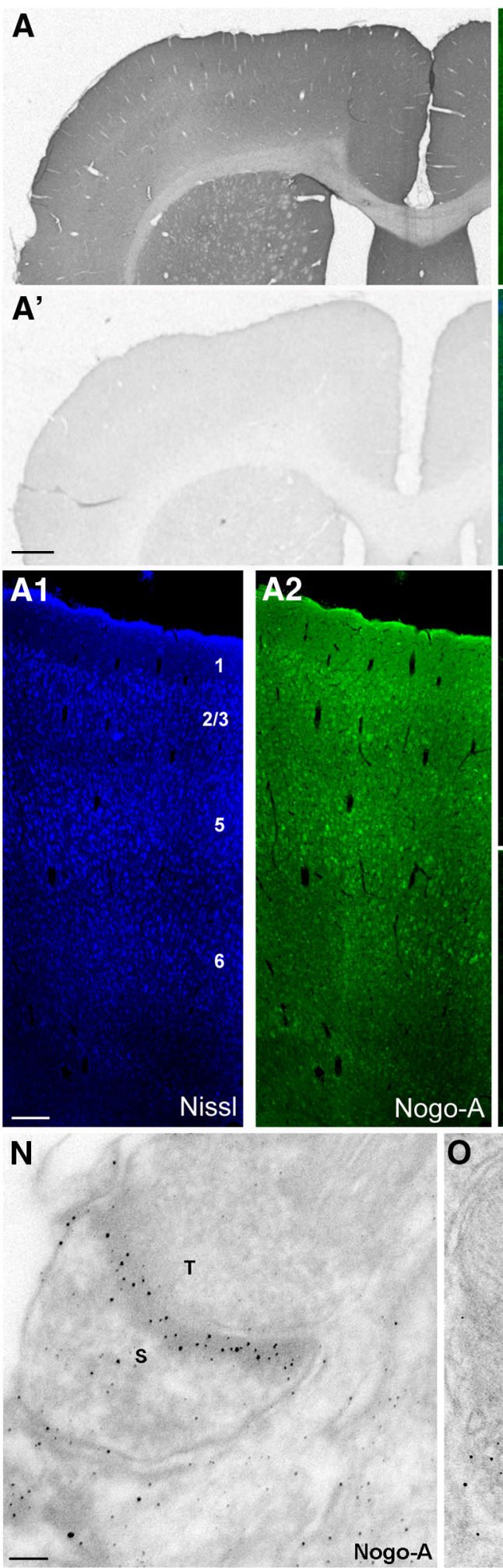
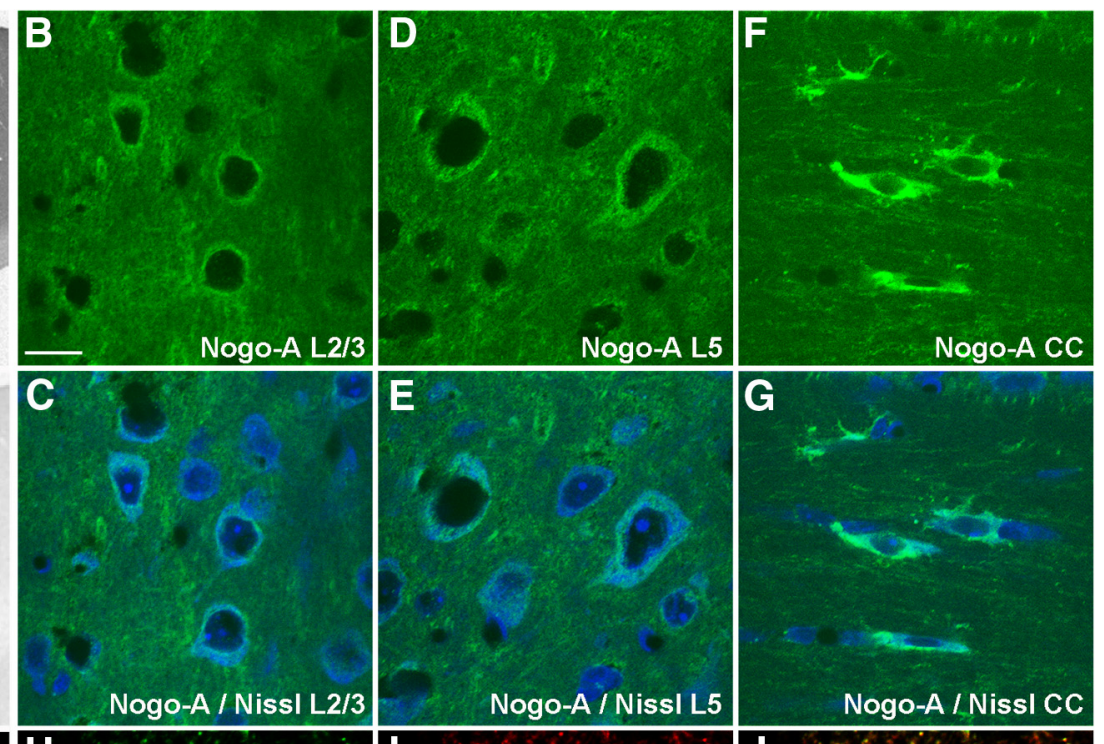

G
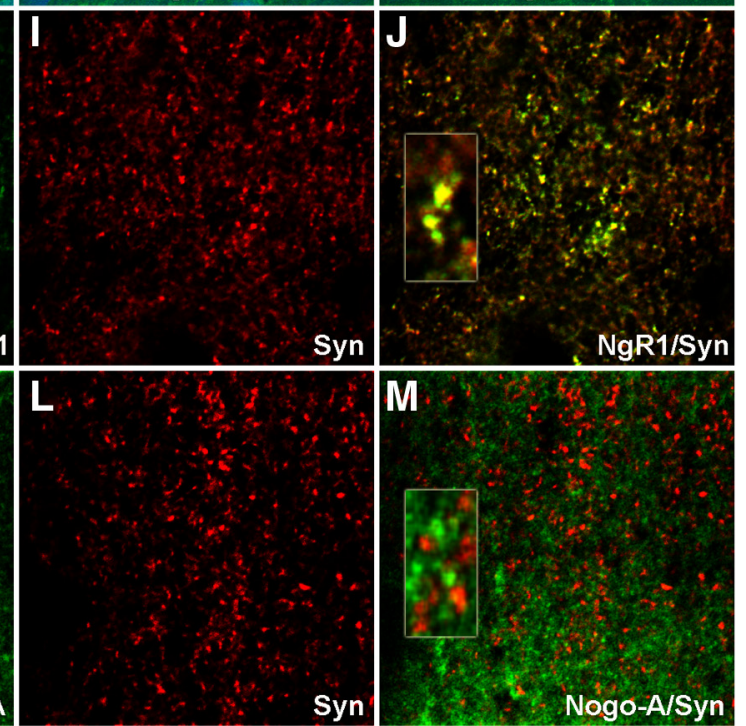

M

S
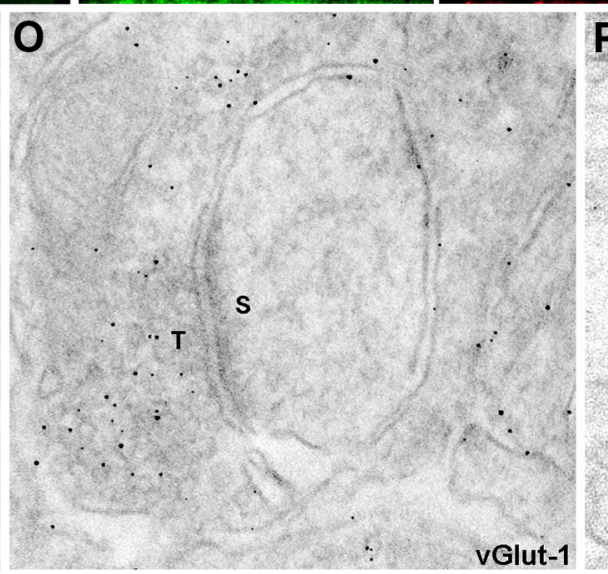

Figure 1. Neuronal and glial expression of Nogo-A and synaptic localization of Nogo-A and NgR 1 in the motor cortex. $\boldsymbol{A}, \boldsymbol{A}^{\prime}$, Overview of a Nogo-A-stained brain section $(\boldsymbol{A})$ and a control section in absence of the primary $\mathrm{Ab}\left(\boldsymbol{A}^{\prime}\right)$. Scale bar, $1 \mathrm{~mm} . \boldsymbol{A} \mathbf{1}, \boldsymbol{A 2}$, Magnified images of the motor cortex stained for Nissl ( $\left.\boldsymbol{A} \mathbf{1}\right)$ and Nogo-A (A2). Cortical layers are indicated in $\boldsymbol{A 1}$. Scale bar, $200 \mu \mathrm{m}$. $\boldsymbol{B}-\boldsymbol{G}$, Immunostaining against Nogo-A revealed expression of the protein in layer $2 / 3$ cells $(\boldsymbol{B}, \boldsymbol{C}$, layer 5 neurons $(\boldsymbol{D}, \boldsymbol{E})$, and glial cells of the corpus callosum $(\boldsymbol{F}, \boldsymbol{G})$. Note the brighter immunofluorescence and higher Nogo-A content in the oligodendrocytes compared with the neurons. $\boldsymbol{C}, \boldsymbol{E}, \boldsymbol{G}$, Overlay of Nogo-A/Nissl staining. Scale bar, $15 \mu \mathrm{m}$. $\boldsymbol{H}-\boldsymbol{M}$, Single-plane confocal images of the neuropil at high magnification immunostained for $\mathrm{NgR} 1(\boldsymbol{H})$, synaptophysin $(\boldsymbol{I})$, and overlay $(\boldsymbol{J})$, as well as for Nogo- $\boldsymbol{A}(\boldsymbol{K})$, synaptophysin $(\boldsymbol{L})$, and overlay $(\boldsymbol{M})$. Insets in $\boldsymbol{J}$ and $\boldsymbol{M}$ show merged images at a higher resolution. Scale bar, $5 \mu \mathrm{m} . \boldsymbol{N}-\boldsymbol{P}$, Representative electron microscopic images showing Nogo-A $(\boldsymbol{N})$, the presynaptic marker vGlut- $1(\boldsymbol{O})$, and $\mathrm{NgR} 1(\boldsymbol{P})$ immunoreactive gold particles in and on the postsynaptic, extrasynaptic, and presynaptic membranes and compartments. Quantification of these results is shown in Table 1. Scale bars, $100 \mathrm{~nm}$. S, Postsynaptic spine, T, presynaptic terminal. 

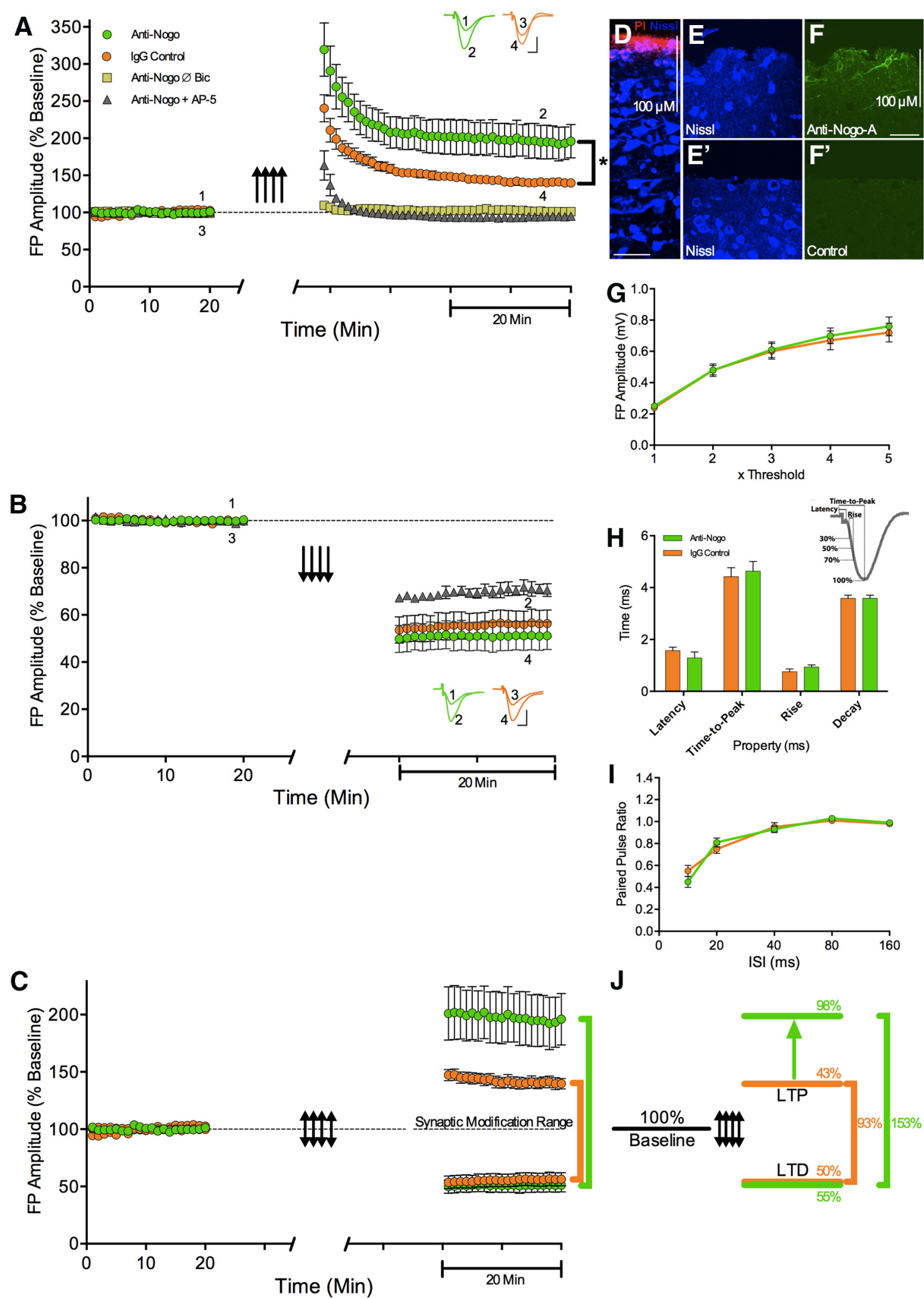

$\mathbf{J}$

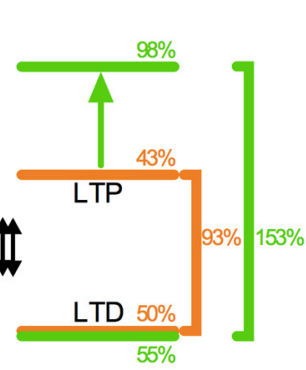

Figure 2. Anti-Nogo-A antibodies increase synaptic plasticity in the rat primary motor cortex. Rat coronal brain slices containing the forelimb region of the primary motor cortex were treated with a function blocking anti-Nogo-A antibody (Ab) (green) or a control Ab (orange). Insets show representative field potential (FP) waveforms obtained from layer 2/3 neurons taken at time points indicated by numbers in each figure. Up arrows: LTP induction, down arrows: LTD induction. $A$, During the last 20 minutes of saturated LTP, a significant difference between anti-Nogo-A treated ( $\mathrm{n}=$ 14) and control Ab treated slices $(n=10)$ is observed $(p=0.038 ; t$-test). LTP induction in anti-Nogo-A treated slices fails in presence of the NMDA receptor (NMDAR) antagonist AP-5 (grey; $n=$ 3). No LTP is induced in anti Nogo-A treated slices in absence of bicuculline (yellow; $n=6$ ). $\boldsymbol{B}$, LTD shows no obvious difference between the anti-Nogo-A ( $n=12$ ) and the control Ab group $(n=9)$ for the last 20 minutes of maximal LTD ( $p=0.59, t$-test). LTD is successfully induced in anti-Nogo-A treated slices in presence of the NMDAR antagonist AP-5 (grey; $n=3$ ). $C, J$, Expansion of the synaptic modification range. The space between LTP and LTD saturation is defined as the synaptic modification range. Treatment with anti-Nogo-A expands LTP saturation (98\%) without altering LTD and by this leads to an enlarged synaptic modification range. $\mathbf{D}-\boldsymbol{F}^{\prime}$, Penetration of anti-Nogo-A antibodies into cortical slices after $1 \mathrm{hr}$ incubation in vitro. $\boldsymbol{D}$, Motor cortex section taken perpendicularly to the slice surface stained with propidium iodide (red/magenta) as a marker for damaged neurons and with Nissl staining (blue) shows that dying cells are (Figure legend continues.) 
coordinates. A small region of skull ( $\sim 300 \mu \mathrm{m}$ in diameter) was manually thinned down to $\sim 20 \mu \mathrm{m}$ in thickness using a high-speed drill and a microknife. To reduce respiration-induced movements, the skull was glued to a $400-\mu \mathrm{m}$-thick stainless steel plate with a central opening for skull access. The plate was screwed to two lateral bars located on either side of the head and fixed to a metal base. The brain of the mouse was then imaged through the thinned skull using a Prairie Ultima IV multiphoton microscope with a Ti-sapphire laser tuned to the excitation wavelength for YFP $(920 \mathrm{~nm})$. Stacks of image planes were acquired with a step size of $0.70 \mu \mathrm{m}$ using a water-immersion objective [60X, numerical aperture (NA) 1.1, infrared Olympus objective] at $3.0 \times$ magnification. For relocation of the same dendrites at subsequent imaging times, an image stack containing the dendritic structures of interest was taken without magnification with a step size of $2.0 \mu \mathrm{m}$ and the surrounding blood vessels were imaged with a CCD camera. The patterns of blood vessels and neuronal processes in this low-resolution image stack were used for relocating the same dendrites at each subsequent imaging session. After imaging, the plate was detached from the skull, the scalp sutured, and the animal was returned to its home cage until the next imaging session.

For figure illustration, we chose relative sparse labeling regions. Maximum projections were made from 3D image stacks containing in-focus dendritic segments of interest. The images were then thresholded, Gaussian filtered, and contrasted for presentation.

Motor skill learning. During pretraining and training, rats were kept on a standard laboratory diet. Water was given ad libitum. To increase the degree of difficulty and complexity of the motor skill task, the behavioral paradigm was adapted from that of Buitrago et al. (2004b). To force the animal to realign its body before each pellet retrieval, animals were first pretrained to run to the rear of the cage and return to the slit opening in the cage front in order to retrieve a new food pellet. During pretraining animals received the pellets only by the tongue and in no case by the forelimb to avoid forelimb motor learning prior to antibody treatment. Once acquainted with the setup and the task, osmotic mini-pumps containing the Abs were then implanted $24 \mathrm{~h}$ after the last pretraining session. One day later, forelimbreaching training was begun by placing the sugar pellet on a small vertical post $1.5 \mathrm{~cm}$ away from the window, a position in which pellets could not be reached by the tongue and were only retrievable by a precise forelimb reaching and grasping movement. Imprecise movements easily displaced the pellet, which was then lost to the animal.

A trial, defined as a new pellet presented to the animal was classified as "successful" (reach, grasp, retrieve, and eat the pellet), "drop" (reach, grasp, and lose pellet during retrieval), or "fail" (knock pellet off the pedestal). A daily session consisted of 150 trials or a maximum time of $1 \mathrm{~h}$ for each animal. To analyze the performance during each daily session (within session analysis), the 150 trials were divided into 25 trial bins and the percentage of successfully grasped pellets for each bin was calculated by dividing the number of successes in the respective bin by the total number of trials on the respective day. Precision and fine-tuning of the movement were investigated through first attempt analysis in a subset of animals: First attempts were considered positive when the animal grasped the pellet in a single monolithic movement execution without disruption, hesitation, or repetition of individual movement components. All experiments were performed in a double-blind manner. Animals were coded with random numbers and the groups were mixed

\footnotetext{
$\leftarrow$

(Figure legend continued.) restricted to the top $10-20 \mu \mathrm{m}$ of the slice. Horizontal scale bar represents $50 \mu \mathrm{m}$. Vertical scale bar represents $100 \mu \mathrm{m}$. $\boldsymbol{E}, \boldsymbol{E}^{\prime}$, Nissl stain of the sections shown in $\boldsymbol{F}, \boldsymbol{F}^{\prime}$ 'showing cells in layer $2 / 3$ of the primary motor cortex. $\boldsymbol{F}$, Representative image of a slice treated with the anti-Nogo-A antibody for 1 hour and immunostained for mouse lgG (light green). Horizontal scale bar represents $50 \mu \mathrm{m}$. $\boldsymbol{F}^{\prime}$, No signal for anti-Nogo-A antibody is detected in a non-treated slice. $G, I$, Input-output strength and paired pulse measurements reveal no significant differences between anti-Nogo-A treated slices and controls. $\boldsymbol{H}$, Kinetics of the fast component of the field response (FR). The latency, time-to-peak, rise time and decay time of the FR kinetics were characterized. No significant difference is seen between anti-Nogo-A and control antibody treated slices. Inset illustrates phases of the field response used for analysis.
}

within the cages. Experimenters were blind to the treatments throughout all phases of the experiment until completion of data analysis.

Dendritic spine imaging in fixed tissue. Coronal slices containing the forelimb area of M1 were prepared as for electrophysiological experiments. The slices were fixed in $4 \%$ PFA overnight at $4{ }^{\circ} \mathrm{C}$ and washed with PBS. Single-cell labeling was performed by shooting dye-coated particles into the slice with a modified "gene gun" (Helios Gene Gun System; Bio-Rad) as described previously (Rauskolb et al., 2010). The slices were subsequently kept in PBS for $3 \mathrm{~d}$ to allow time for the dye to diffuse. The slices were postfixed in $4 \%$ PFA, washed, and stained with DAPI to enable the identification of the cortical layers. Layer $2 / 3$ neurons from the forelimb area of M1 were imaged with a BX61WI FLUOVIEW 1000 (FV1000) Olympus confocal microscope. Image stacks of defined dendritic stretches from the midapical dendritic parts were acquired using a $40 \times$ oil objective (NA 1.3), $z$-step of 0.5 $\mu \mathrm{m}$, and a magnification of $4 \times$.

Detection of the monoclonal anti-Nogo-A Ab in pump infused brains and spinal cords. Four rats received intrathecal pump infusions of the mouse monoclonal anti-Nogo-A Ab 11C7 for $6 \mathrm{~d}$ and four untreated control animals were perfused under anesthesia with $4 \%$ buffered PFA. Fortymicrometer cryostat sections of the brains and spinal cords were stained free floating with a rat adsorbed anti-mouse IgG Ab coupled to biotin (1:300; Jackson ImmunoResearch), followed by the ABC Elite-DAB peroxidase detection system (Vector Laboratories). In four of four antiNogo-A-infused animals, we could detect mouse IgG immunoreactivity in the spinal cord and in all brain regions. The parallel processed control animal showed no signal except a few endogenous peroxidase-positive erythrocytes. Images of stained sections were acquired using a cooled CCD camera (Cool Snap HQ; Photometrics) and the image analysis software MCID (Elite version 7.0; Imaging Research).

Detection of infused anti-Nogo-A Abs in brain and spinal cord by Western blot. After intrathecal infusion with the anti-Nogo-A Ab for $6 \mathrm{~d}$, rats were briefly anesthetized with isofluorane and decapitated. The brain and spinal cord were quickly removed, placed on ice for dissection, snap frozen (100-200 $\mathrm{mg}$ in weight), and stored at $-80^{\circ} \mathrm{C}$ until extraction. Tissue lysates were prepared as described previously (Kempf et al., 2014). Briefly, the tissue was homogenized in a weight-to-volume ratio of $1: 3$ in modified RIPA buffer containing $150 \mathrm{~mm}$ sodium chloride, $50 \mathrm{~mm}$ Tris$\mathrm{HCl}, \mathrm{pH}$ 8.0, $1 \mathrm{~mm}$ phenylmethylsulfonyl fluoride, $1 \% \mathrm{NP}-40,0.5 \%$ sodium deoxycholic acid, $0.1 \%$ sodium dodecylsulfate, and protease inhibitors (Roche). The homogenate was centrifuged to pellet the cell and tissue debris (maximally $15-25 \%$ of the total homogenate). The protein concentration in the supernatant (between $75 \%$ and $85 \%$ of total homogenate) was measured with the RC-DC Protein Assay Kit (Bio$\mathrm{Rad})$. Then, $120 \mu \mathrm{g}$ of protein from each brain region and spinal cord supernatant was run per lane of a Nupage $4-12 \%$ Bis-Tris polyacrylamide gel (Invitrogen). To detect the anti-Nogo-A Ab, a horse-antimouse IgG-rat absorbed-biotinylated secondary Ab $(0.5 \mu \mathrm{g} / \mathrm{ml}$, catalog \#BA-2001; Vector Laboratories) was used followed by detection of the ABC complex (ABC Complex Elite Kit; Vector Laboratories).

Statistical analysis. For in vivo motor skill learning, two-way mixed ANOVA (between-subjects factor: group of treatment; withinsubjects factor: day of training) was applied. If a significant effect was found for a factor, post hoc tests were performed using Bonferroni's correction for multiple comparisons. For all other experiments, twosampled, two-tailed $t$ tests with unequal sample size were used. Normality and equal variance hypotheses were tested by Kolmogorov-Smirnov test and $F$ test, respectively. All values in the Results section are given as mean \pm SEM.

\section{Results}

\section{Distribution and synaptic localization of Nogo-A and NgR1}

In addition to oligodendrocytes, Nogo-A and NgR1 are known to be expressed in the CNS in subtypes of neurons and at synapses (Josephson et al., 2001; Huber et al., 2002; Wang et al., 2002; Jin et al., 2003; Raiker et al., 2010; Rolando et al., 2012; Mironova and Giger, 2013; Petrinovic et al., 2013). Immunostaining of cryosections of the adult rat motor cortex 
A

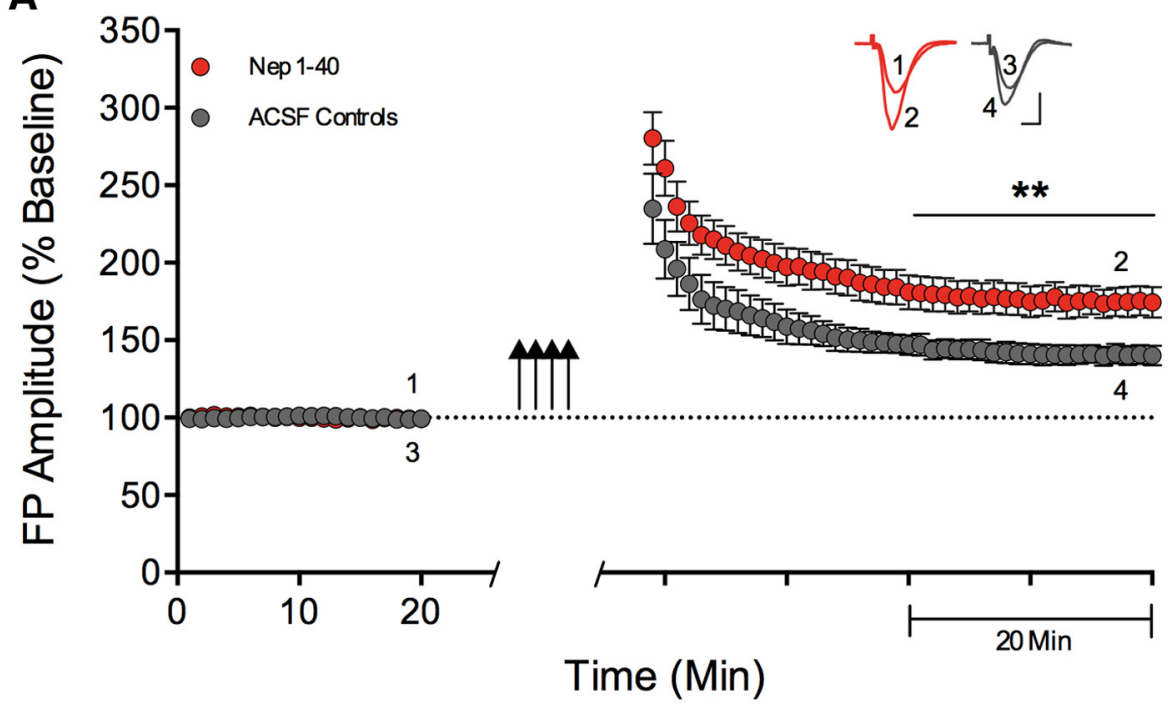

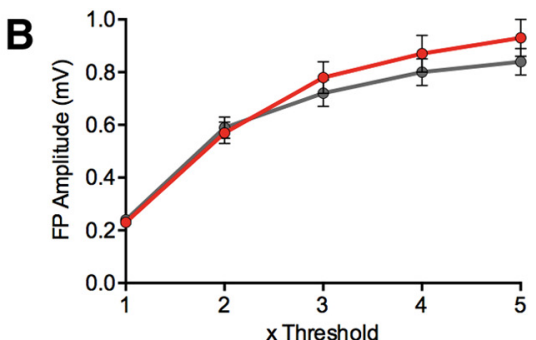
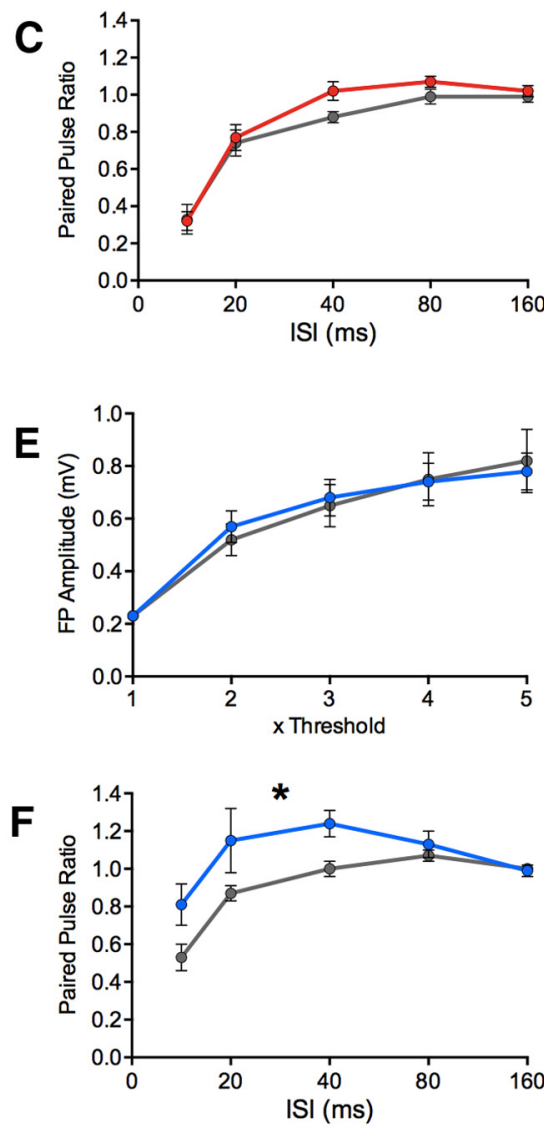

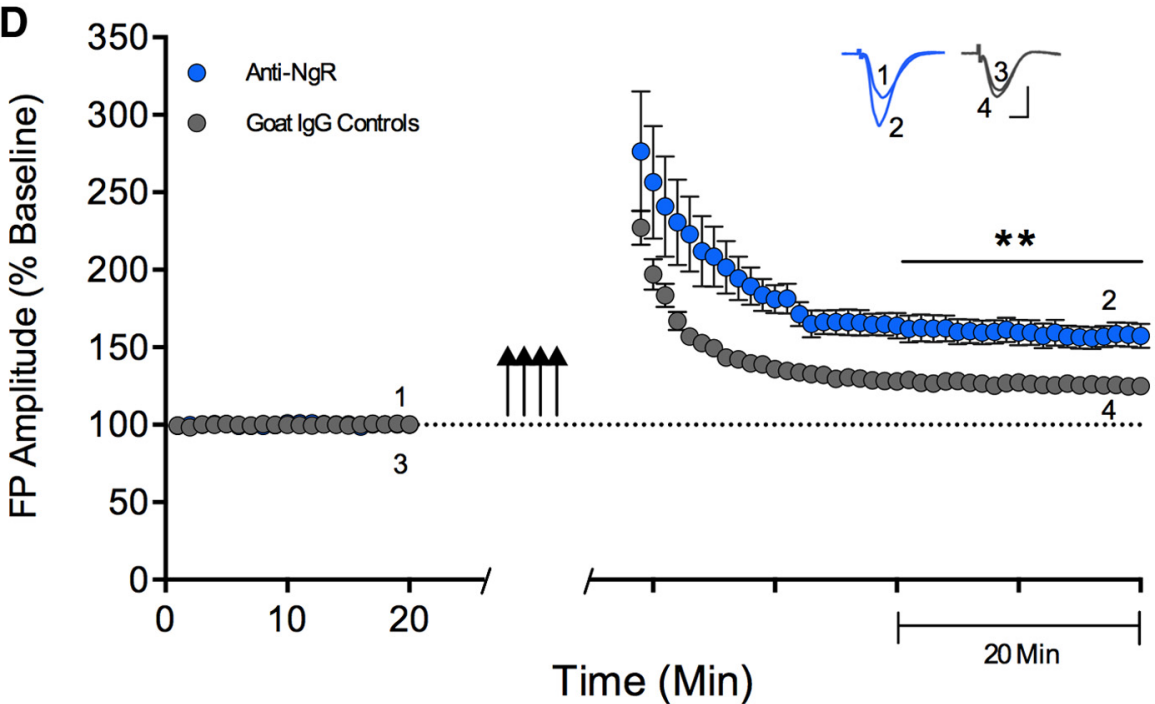

Figure 3. Blockade of the Nogo receptor NgR1 enhances LTP in the rat primary motor cortex. Coronal brain slices containing the main forelimb motor cortex were treated with the Nogo-66 antagonist peptide Nep 1- 40 or a functional Ab against NgR1. Insets show representative FP waveforms taken at the time points indicated by numbers in each figure. Up arrows, LTP induction. $\boldsymbol{A}-\boldsymbol{C}$, During the last 20 min of saturated LTP, a significant difference between Nep 1-40-treated slices (red; $n=7$ ) and controls (ACSF; gray; $n=9)$ is observed $(p<0.005 ; t$ test). 10 strength and paired-pulse analysis reveals no significant differences between Nep 1-40-treated slices and controls. D-F, During the last 20 min of saturated LTP, a significant difference between anti-NgR1treated (blue; $n=8$ ) and lgG control treated slices (gray; $n=10)$ is observed ( $p<0.005 ; t$ test). 10 strength reveals no significant difference between anti-NgR1 and control-Ab-treated slices. Paired-pulse analysis reveals significantly higher ratios for anti-NgR1-treated slices compared with $\lg G$ controls $(p<0.05) .{ }^{*} p<0.05 ;{ }^{* *} p<0.01$.

showed Nogo-A expression in a subset of pyramidal neurons in layers $2 / 3$ and 5 (Fig. $1 A-E$ ), as well as strong staining in oligodendroglial cells in the corpus callosum (Fig. $1 F, G)$. Coimmunostaining of the sections with the presynaptic marker synaptophysin revealed frequent Nogo-A-positive puncta juxtaposed to synaptophysin-positive structures (Fig. $1 I, K-M$ ), whereas most NgR1-positive puncta were colocalized with synaptophysin (Fig. $1 \mathrm{H}-\mathrm{J}$ ). Immunogold electron microscopy showed the presence of Nogo-A and NgR1 both in presynaptic and postsynaptic membranes, but with higher Nogo-A levels postsynaptically and enrichment of $\mathrm{NgR} 1$ presynaptically (Fig. $1 \mathrm{~N}, P$ ). Presynaptic structures were confirmed by the presynaptic marker vGlut-1 (Fig. 1O). Quantification of these results is shown in Table 1.
Neutralization of Nogo-A enlarges the synaptic modification range in the motor cortex through LTP enhancement Fresh, $500 \mu \mathrm{m}$ slices of young adult (5-6 weeks old) rat brains containing the sensory-motor forelimb area were pretreated for at least $1 \mathrm{~h}$ with a function-blocking monoclonal Nogo-A $\mathrm{Ab}$ (Oertle et al., 2003; Liebscher et al., 2005) or a control IgG Ab at a concentration of $5 \mu \mathrm{g} / \mathrm{ml}$. Ab penetration into the slice to a depth of 60-100 $\mu \mathrm{m}$ was confirmed immunohistochemically (Fig. $2 D-$ $\left.F^{\prime}\right)$. Synaptic plasticity was determined by stimulating horizontal fibers in cortical layer $2 / 3$ and measuring the FP amplitude at a distance of $500 \mu \mathrm{m}$ from the stimulation site. LTP was induced with a theta-burst stimulation protocol under local application of a $\mathrm{GABA}_{\mathrm{A}}$ antagonist. Repeated trains of stimuli were applied until saturation of LTP was reached as described previously 
Table 2. Two-photon in vivo imaging information

\begin{tabular}{lllll}
\hline Conditions & $\begin{array}{l}\text { Animal } \\
\text { Control }\end{array}$ & $\begin{array}{l}\text { Location of imaged } \\
\text { region }(\mathrm{mm})^{a}\end{array}$ & $\begin{array}{l}\text { Total spine } \\
\text { no. }\end{array}$ & $\begin{array}{l}\text { Total dendritic } \\
\text { segment no. }\end{array}$ \\
\hline & 1 & $1.5 \mathrm{~L}, 1.0 \mathrm{~A}$ & 209 & 37 \\
& 2 & $1.4 \mathrm{~L}, 1.1 \mathrm{~A}$ & 137 & 21 \\
& 3 & $1.5 \mathrm{~L}, 0.9 \mathrm{~A}$ & 134 & 30 \\
IgG control & 1 & $1.5 \mathrm{~L}, 0.8 \mathrm{~A}$ & 104 & 31 \\
& 2 & $1.8 \mathrm{~L}, 1.4 \mathrm{~A}$ & 125 & 12 \\
& 3 & $1.5 \mathrm{~L}, 0.9 \mathrm{~A}$ & 117 & 13 \\
Anti-Nogo & 1 & $1.6 \mathrm{~L}, 0.8 \mathrm{~A}$ & 113 & 23 \\
& 2 & $1.7 \mathrm{~L}, 1.3 \mathrm{~A}$ & 125 & 12 \\
& 3 & $1.4 \mathrm{~L}, 1.0 \mathrm{~A}$ & 123 & 17 \\
& 4 & $1.5 \mathrm{~L}, 1.1 \mathrm{~A}$ & 115 & 16 \\
\hline
\end{tabular}

Imaging location, total spine number, and total dendritic segment number are shown for each animal under different experimental conditions.

${ }^{a}$ The location of the imaged region is presented as the lateral distance $(\mathrm{L})$ from the midline and the anterior distance (A) from the bregma.

(Rioult-Pedotti et al., 1998; Rioult-Pedotti et al., 2000). AntiNogo-A treated slices showed a significant increase in synaptic strength during the final $20 \mathrm{~min}$ of saturated LTP (198.7 \pm 22.7\%, $n=14$ slices from 9 animals; Fig. $2 A$ ) compared with control IgG-Ab-treated slices $(142.3 \pm 4.9 \%, n=10$ slices from 8 animals; $p=0.038, \mathrm{df}=13.9, t$ test $)$. To determine whether the effect of anti-Nogo-A Abs on LTP was NMDA receptor (NMDAR)-dependent, NMDARs were blocked with AP-5 in the presence of the anti-Nogo-A Ab; no LTP induction was observed (93.74 $\pm 0.91, n=3$ slices from 3 animals; Fig. $2 A$ ). A possible role of the GABAergic system could not be analyzed because, as shown in earlier studies (Hess et al., 1996) and confirmed here, no LTP could be induced in the motor cortex without reducing GABAergic inhibition by local application of bicuculline (102.4 $\pm 2.4 \%$ during final 20 min, $n=6$ slices from 6 animals; Fig. 2A).

LTP adapts synaptic transmission in response to synaptic impulse traffic. The opposite event to LTP is LTD. NgR1 was shown to influence LTD induction in the hippocampal Schaffer collateral pathway (Lee et al., 2008; Raiker et al., 2010), whereas the acute neutralization of Nogo-A did not affect LTD expression (Delekate et al., 2011). To investigate the influence of antiNogo-A on LTD in the motor cortex, LFS ( $2 \mathrm{~Hz}$ for $15 \mathrm{~min}$ ) was applied 4 times to the rat sensory-motor cortex slices as described previously (Rioult-Pedotti et al., 2000). No difference in LTD was observed between anti-Nogo-A-treated and control-Ab-treated slices (anti-Nogo-A: $50.9 \pm 5.9 \% ; n=12$ slices from 10 animals; control Ab: $55.4 \pm 5.6 \% ; n=9$ slices from 9 animals; $p=0.59$; $\mathrm{df}=18, t$ test; Fig. $2 B$ ). Partial involvement of NMDARs in the LTD effect of anti-Nogo-A Abs was suggested by successful LTD induction in the presence of AP-5; however, LTD under these conditions was less than with active NMDARs $(69.54 \pm 2.05 ; n=$ 3 slices from 3 animals; Fig. 2B).

The strong enhancement in saturated LTP leads to an enlargement of the synaptic modification range upon anti-Nogo-A Ab treatment, as illustrated in Figure 2, $C$ and $J$ (total range span in percent: anti-Nogo-A: 153\%; control Ab: 93\%).

To determine whether the observed increase in synaptic potentiation could result from alterations in baseline synaptic transmission, we recorded input-output (I-O) curves and found no significant differences between anti-Nogo-A- and control-Abtreated slices ( $n=15$ vs $15 ; p=0.74$ between-subjects; $\mathrm{df}=1$; 2-way mixed ANOVA; Fig. $2 G$ ). We also analyzed the kinetics of the field response, in particular the different phases of its fast component, as indicated in Figure $2 \mathrm{H}$. We found no significant differences between anti-Nogo-A and control-Ab-treated slices
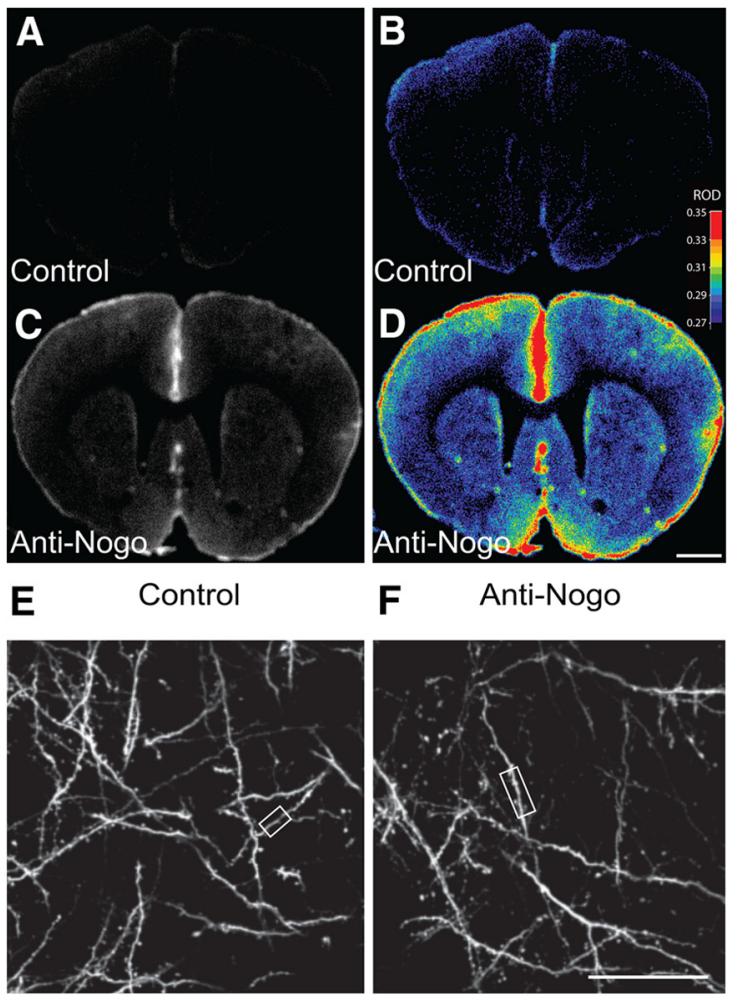

F Anti-Nogo

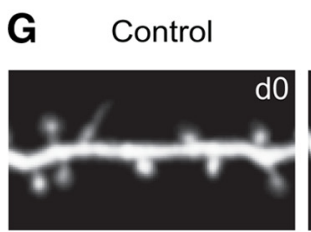

H Anti-Nogo
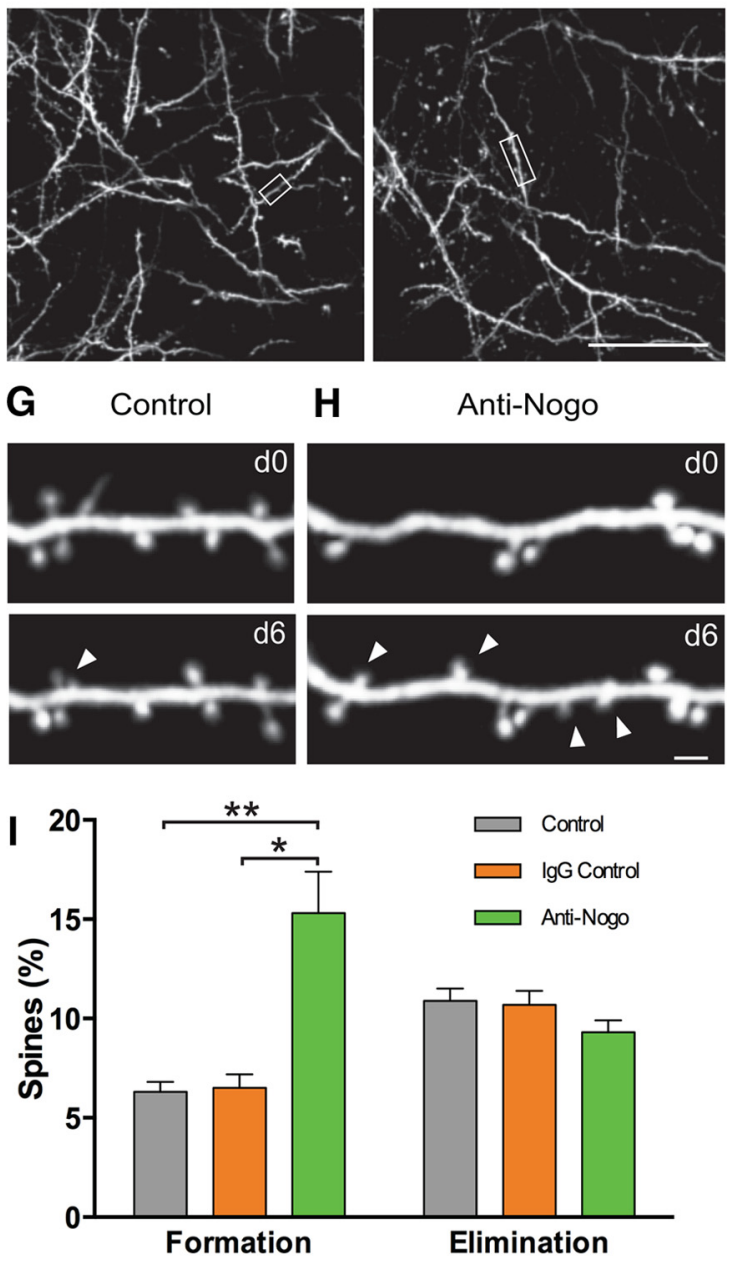

Figure 4. Functional blockade of Nogo-A increases spine formation in vivo. $A-D$, Black and white $(A, C)$ and corresponding color-coded sections $(\boldsymbol{B}, \boldsymbol{D})$ of a mouse brain after $6 \mathrm{~d}$ of intrathecal anti-Nogo-A Ab infusion $(\boldsymbol{C}, \boldsymbol{D})$ or a noninfused mouse $(\boldsymbol{A}, \boldsymbol{B})$ processed for the detection of mouse $\lg G$ by immunoperoxidase. No $A b$ is detected in the control brain $(A, B)$. In the antiNogo-A-infused animal $(\boldsymbol{C}, \boldsymbol{D})$, anti-Nogo-A Abs are detected in the superficial layers and in deeper brain structures. Scale bar, $0.5 \mathrm{~mm}$. ROD, Relative optical density. $\boldsymbol{E}, \boldsymbol{F}$, Lowmagnification $2 D$ projections from $3 D$ stacks of dendritic branches in the motor cortex of mice treated with lgG control Abs $(\boldsymbol{E})$ and anti-Nogo-A Abs $(\boldsymbol{F})$. Scale bar, $20 \mu \mathrm{m}$. $\boldsymbol{G}, \boldsymbol{H}$, Highermagnification views of dendritic segments shown in the white boxes of $\boldsymbol{E}$ and $\boldsymbol{F}$ at day 0 (d0) and d6. Arrowheads, Newly formed spines. Scale bar, $2 \mu \mathrm{m}$. I, Percentage of spine formation (antiNogo-A vs control Ab: $p=0.006$; anti-Nogo-A vs control: $p=0.820$ ) and elimination $(p>0.1$, all pair comparisons) over $6 \mathrm{~d}$ in untreated (gray; $n=4)$, control-Ab-treated (orange; $n=3$ ), and anti-Nogo-A-treated animals (green; $n=4$ ). ${ }^{*} p<0.05$; ${ }^{* *} p<0.01$. 

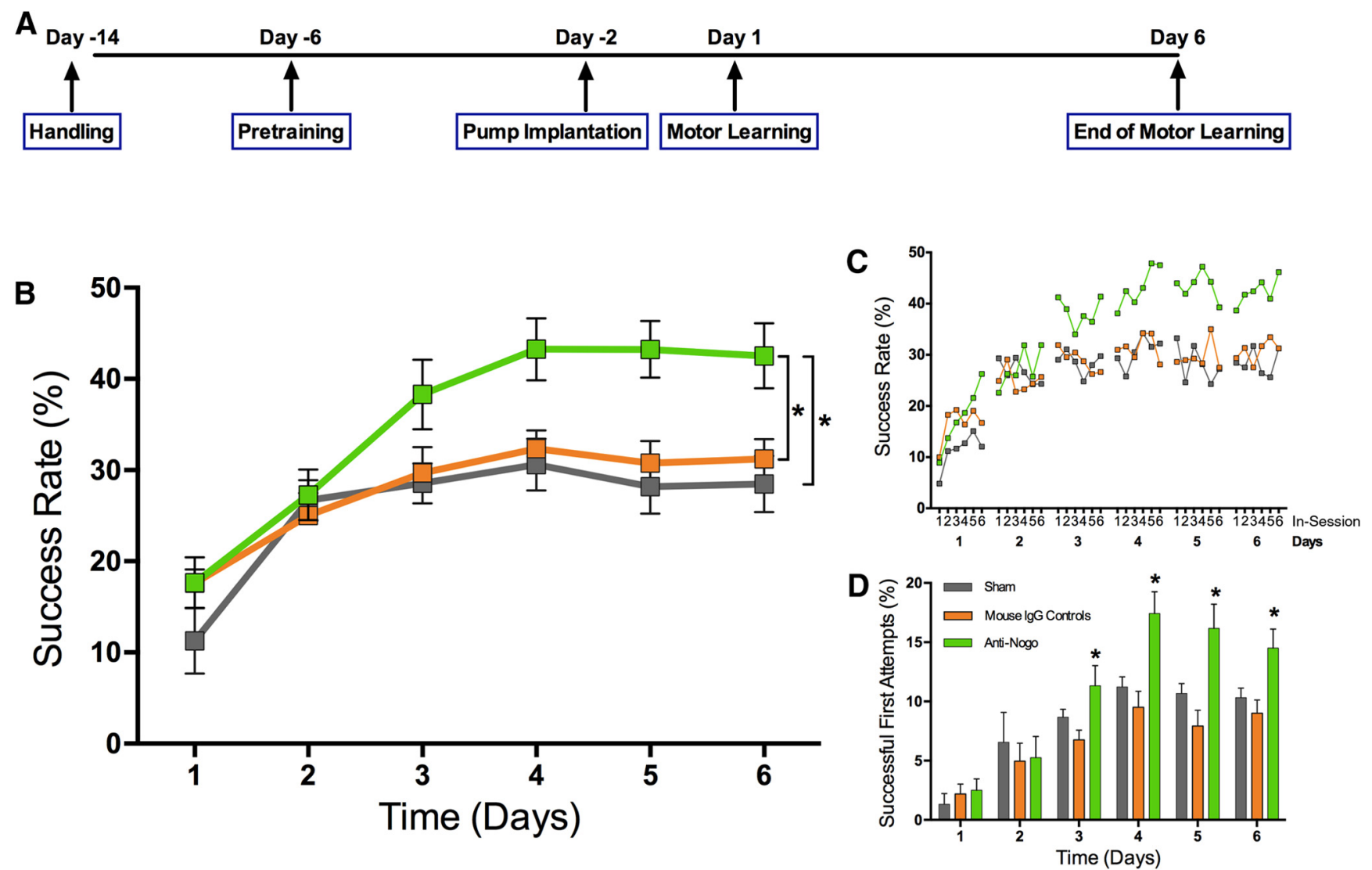

Figure 5. Anti-Nogo-A Ab treatment improves motor skill learning in vivo. Rats were exposed to a complex precision forelimb-reaching task while receiving anti-Nogo-A Abs (green; $n=13$ ), control Abs (orange; $n=16$ ), or no Ab treatment (sham, gray; $n=9$ ). $\boldsymbol{A}$, Experimental timeline. Day 1 refers to the first day of motor learning. The Ab pumps were implanted $2 \mathrm{~d}$ before the first training day. $\boldsymbol{B}$, Motor skill acquisition over $6 \mathrm{~d}$ shown as pellet-grasping success rates over 150 pellets/d. Anti-Nogo-A-treated animals show significantly improved motor learning compared with control lgG-treated and sham animals ( $p=0.0067$; 2 -way mixed ANOVA). No significant difference was observed between lgG controls and sham animals. $C$, Within-day success rates shown in six bins of 25 pellets/d illustrate improvement in motor learning throughout a daily session (in-session). Anti-Nogo-A-treated animals finish with higher scores toward the end of the first $2 \mathrm{~d}$ and reach higher success rates throughout all phases between days 3 and 6 . D, Successful first attempts are shown as a measure for fine-tuned movement learning. Animals receiving anti-Nogo-A Ab ( $n=8$ ) show significantly higher successful first attempt values on days $3-6$ compared with control lgG Ab-treated rats $(n=8 ; p=0.089 ; 2$-way mixed ANOVA, Bonferroni's correction) and sham controls ( $n=9)$. ${ }^{*} p<0.05$.

(mean values for anti-Nogo-A vs control IgG Ab for onset latency: $1.29 \pm 0.23$ vs $1.57 \pm 0.13 \mathrm{~ms}, p=0.32$; time-to-peak: $4.64 \pm 0.37$ vs $4.42 \pm 0.35 \mathrm{~ms}, p=0.67$; rise time: $0.94 \pm 0.08$ vs $0.76 \pm 0.1 \mathrm{~ms}, p=0.18$; decay time: $3.59 \pm 0.12$ vs $2.96 \pm 0.43$ $\mathrm{ms}, p=0.19$; in all cases, $\mathrm{df}=14, t$ test $)$.

Paired-pulse facilitation is a presynaptic form of short-term plasticity characterized by a transient increase in presynaptic $\left[\mathrm{Ca}^{2+}\right]_{\mathrm{i}}$ and neurotransmitter release induced by two closely separated stimuli (Schulz et al., 1994). We neutralized Nogo-A to test a possible presynaptic function and found no difference in the paired-pulse ratio between anti-Nogo-A-treated slices and control Abs (anti-Nogo-A: $n=12$, IgG control Ab: $n=11 ; p=0.83$, between-subjects; $\mathrm{df}=1$; 2-way mixed ANOVA; Fig. $2 I$ ).

In summary, these results demonstrate that functional blockade of Nogo-A leads to an enlarged synaptic modification range through an increase of saturated LTP without affecting LTD (Fig. $2 C, J)$. Baseline synaptic transmission, presynaptic properties of short-term plasticity, and fast kinetics of the field response are not influenced by anti-Nogo-A Ab treatment.

\section{Blockade of the Nogo receptor NgR1 increases LTP in the motor cortex}

Nep 1-40 is a 40 amino-acid peptide from the extracellular loop region of Nogo-A that binds to the Nogo receptor NgR1 and acts as a competitive antagonist (GrandPré et al., 2002). We evaluated the impact of Nep 1-40 on synaptic strengthening at the layer $2 / 3$ horizontal fiber pathway in the motor cortex. Protocols were identical to the anti-Nogo-A Ab experiments; Nep 1-40 was used at a concentration of $300 \mathrm{~nm}$. Figure $3 A$ shows a significant increase $(p=0.0047, \mathrm{df}=15, t$ test $)$ in the magnitude of LTP saturation for Nep 1-40-treated slices (176.4 $\pm 10.0 \%, n=7$ slices from 7 animals) compared with controls (141.8 $\pm 6.3 \%$, $n=9$ slices from 6 animals). No influence of Nep 1-40 was observed on baseline synaptic transmission ( $p=0.48$, betweensubjects, $\mathrm{df}=1 ; 2$-way mixed ANOVA; Fig. $3 B$ ) and paired-pulse facilitation ( $n=7$ vs $7 ; p=0.30$, between-subjects; $\mathrm{df}=1 ; 2$-way mixed ANOVA; Fig. $3 C$ ). Next, we used a function-blocking Ab against NgR1 and a goat IgG Ab as control at a concentration of 5 $\mu \mathrm{g} / \mathrm{ml}$. Abs against NgR1 yielded significantly higher levels of LTP saturation compared with control IgG Ab (anti-NgR1: $159.52 \pm 7.79 \%$, 8 slices from 8 animals, control Ab: $126.45 \pm$ $2.07 \%, 10$ slices from 9 animals; $p=0.0032, \mathrm{df}=7.8, t$ test; Fig. 3D). Anti-NgR1 Abs did not affect baseline synaptic transmission (anti-NgR1: $n=15$; IgG: $n=17 ; p=0.94$, between-subjects; df $=1 ; 2$-way mixed ANOVA; Fig. $3 E$ ), but paired-pulse measurements revealed significantly higher ratios in anti$\mathrm{NgR} 1$-treated slices compared with the respective control Abs ( $p=0.029$, between-subjects; $\mathrm{df}=1,2$-way mixed ANOVA; Fig. $3 F)$. 


\section{Sham}

A
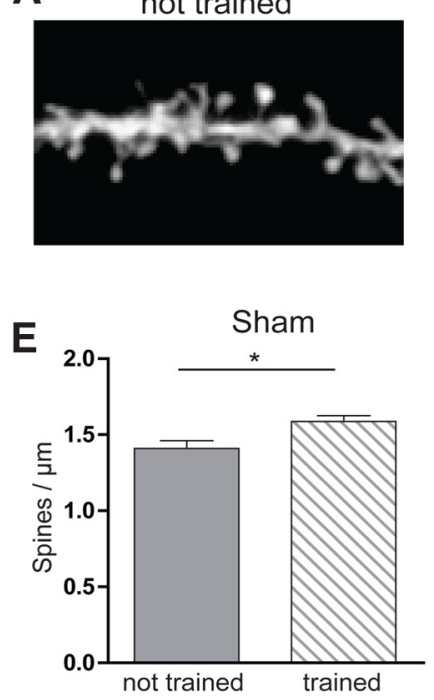

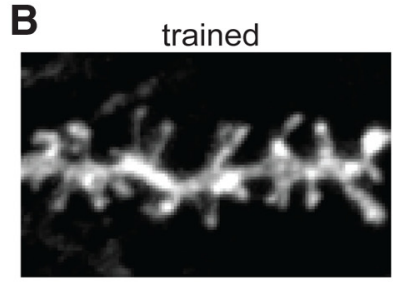

F

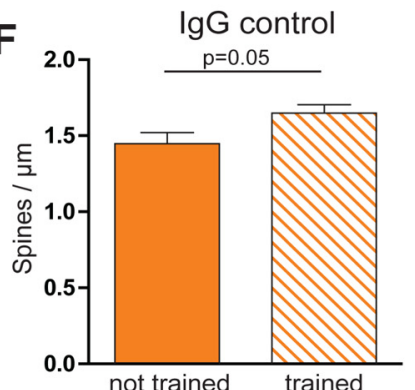

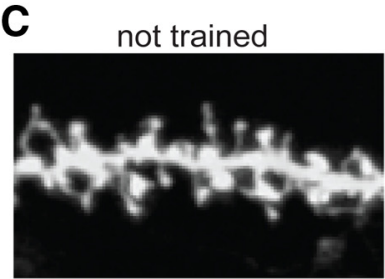

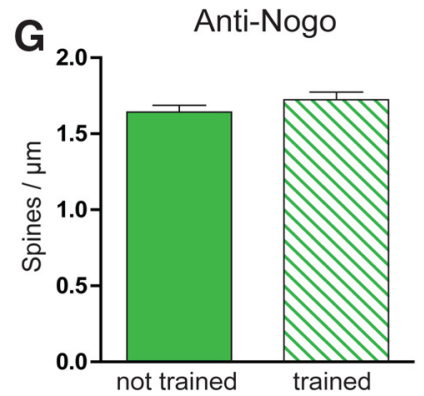

Anti-Nogo
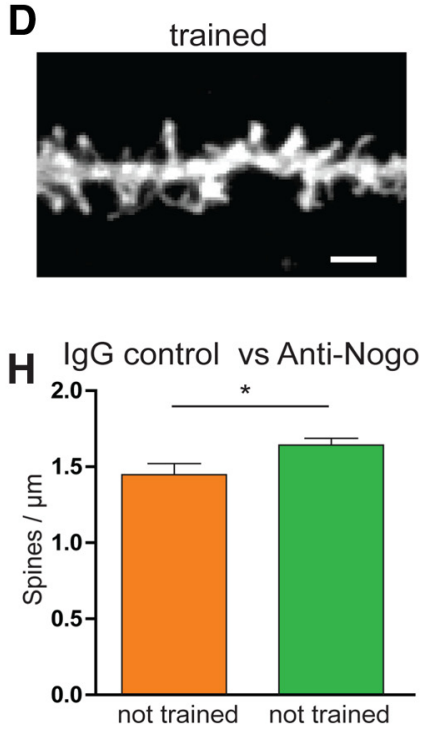

Figure 6. Training and anti-Nogo-A Ab treatment affect spine density. $\boldsymbol{A}-\boldsymbol{D}$, Representative images of the apical dendritic regions labeled with Dil, comparison of the trained versus untrained hemisphere for sham control versus Nogo-A-blocking Abs. Scale bar, $2 \mu \mathrm{m}$. $\boldsymbol{E}-\mathbf{G}$, Quantified data showing dendritic spine density for the apical dendrites of layer $2 / 3$ pyramidal neurons in the trained versus untrained hemisphere in sham animals $[n=14$ trained (t), $n=13$ untrained (ut)], control-Ab-treated animals ( $n=12$ for t, $n=6$ for ut), and anti-Nogo-A-treated animals ( $n=15$ for t, $n=20$ for ut). $\boldsymbol{H}$, Quantification showing spine density for the untrained hemisphere of control versus anti-Nogo-A Ab. ${ }^{*} p<0.05$.

In summary, blockade of NgR1 increases synaptic strength and affects presynaptic properties without altering baseline synaptic transmission.

\section{Anti-Nogo-A Ab treatment increases spine formation in motor cortex layer 5 neurons in vivo}

To gain insights into the effects induced by Nogo-A neutralization on synaptic structures in the motor cortex in vivo, we treated animals with function blocking anti-Nogo-A or control Abs by continuous intrathecal infusion over $6 \mathrm{~d}$ (Fig. $4 A-D)$ via intrathecal administration and used in vivo transcranial two-photon microscopy (Xu et al., 2009) to repeatedly image the apical dendrites of YFP-expressing layer 5 pyramidal neurons (1-monthold mice, YFP-H line; Feng et al., 2000). Layer 5 neurons were analyzed in this experiment because fluorescent visualization of cortical layer $2 / 3$ cells is only possible through electroporation, which allows the analysis of only a small fraction of cells. Treatment with anti-Nogo-A Abs for $6 \mathrm{~d}$ significantly increased the amount of new spines added during that period compared with mice treated with control Abs or mice without any treatment (anti-Nogo-A: $15.3 \pm 4.2 \%, n=4$; control IgG Ab: $6.5 \pm 1.2 \%$, $n=3$; untreated control: $6.3 \pm 0.9 \%, n=4 ; p=0.018, \mathrm{df}=5$, anti-Nogo-A vs control Ab; $p=0.006, \mathrm{df}=6$, anti-Nogo-A vs control; $p=0.820, \mathrm{df}=5$, control Ab vs control; Fig. $4 I$ ). In contrast to spine formation, spine elimination during the same $6 \mathrm{~d}$ period was comparable among the 3 experimental groups (anti-Nogo-A: $9.3 \pm 1.1 \%$, control Ab: $10.7 \pm 1.2 \%$, untreated control: $10.9 \pm 1.2 \% ; p>0.1$, all pair comparisons).

Together, these results show a negative effect of Nogo-A signaling in regulating spine formation of layer 5 neurons in the motor cortex.

Anti-Nogo-A Ab treatment improves skilled forelimb motor learning in vivo

Adult male rats were trained on a skilled forelimb-reaching task in which a sugar pellet placed on a pedestal had to be accessed through a narrow window, grasped, brought to the mouth, released, and eaten. This task was more difficult than the classical reaching paradigm from a platform and required the acquisition of high precision in the execution of all movement components (Buitrago et al., 2004b). To allow recovery after the pump implantation, animals started the first learning session $2 \mathrm{~d}$ after the surgery. From this time on, they were trained over $6 \mathrm{~d}$ with 150 reaches daily. They received function blocking anti-Nogo-A or control Abs by continuous intrathecal infusion during the $6 \mathrm{~d}$ period (Fig. 5A). Abs reached the motor cortex from the pump catheter over the thoracic spinal cord, as described in "AntiNogo-A Ab treatment modulates spine density upon motor learning in rats." To assess possible effects of the catheter, pump, or control $\mathrm{Ab}$ on motor learning, we trained an additional sham group. Figure $5 B$ shows the pellet-grasping success rates for the three groups. Rats started with low success rates on day 1 (antiNogo-A: $17.7 \pm 2.7 \%$, control IgG Ab: $17.6 \pm 1.5 \%$, sham: $11.3 \pm 3.6 \%)$ and reached scores of $\sim 25 \%$ on the second session (anti-Nogo-A: $27.3 \pm 2.7 \%$, control IgG Ab: $25.0 \pm 2.5 \%$, sham: $26.7 \pm 2.2 \%)$. On the subsequent days, the anti-Nogo-A group showed a significantly steeper learning curve and reached a higher level of successful performance between days 4 and 6 compared with both control groups (anti-Nogo-A: $42.8 \pm 3.3 \%$, control IgG Ab: $31.5 \pm 2.2 \%$, sham: $29.1 \pm 3.0 \%$ average success rates for day 4-6; $p=0.0067,2$-way mixed ANOVA, betweensubjects; $95 \%$ confidence interval $=6.99$; Bonferroni corrected). Control IgG-treated and sham animals did not significantly differ in their performance.

Several lines of research suggest that motor skill acquisition consists of a slow phase (between training sessions) and a fast phase (within an individual training session) (Karni et al., 1998; Buitrago et al., 2004a). Improvement in motor learning within a session was assessed by separating the 150 reaches per day into 25-trial bins and dividing the success scores within a bin by the total number of trials on the respective day (Fig. 5C). Anti-NogoA-treated rats finished each training session with higher scores 


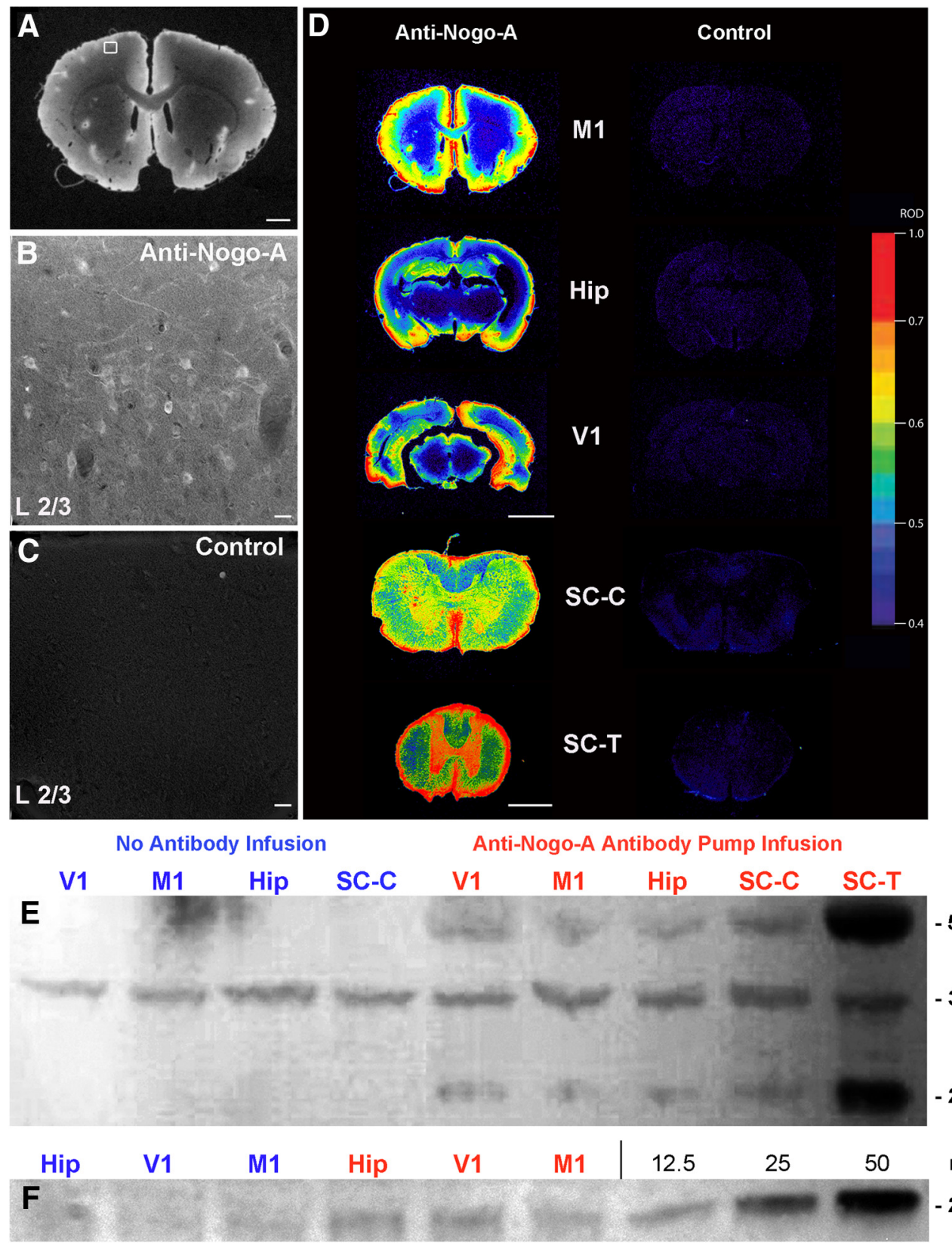

- 50kD Anti-Nogo-A (H-Chain)

- 37kD GAPDH

- 25kD Anti-Nogo-A (L-Chain)

ng/Lane Purified Anti-Nogo-A Antibody

- 25kD Anti-Nogo-A (L-Chain)

Figure 7. Penetration of anti-Nogo-A Abs in rat CNS tissue after $6 \mathrm{~d}$ of intrathecal infusion over the thoracic spinal cord. $A$, Inverted picture of immunoperoxidase detection of the mouse anti-Nogo-A Ab shows graded penetration from the outer CSF spaces into the brain. Scale bar, $1 \mu \mathrm{m}$. $\boldsymbol{B}$, Higher-magnification view of motor cortex layer $2 / 3$ region indicated by the white box in $\boldsymbol{A}$ shows cellular uptake of the anti-Nogo-A Ab in addition to diffuse tissue staining. C, No signal was detected in untreated control animals in the same layers. Scale bars in $\boldsymbol{B}$ and $\boldsymbol{C}$ represent $30 \mu \mathrm{m}$. D, Color-coded intensity of immunoperoxidase reaction for the mouse anti-Nogo-A Ab in the CNS of a rat infused with anti-Nogo-A Ab (left row) and an untreated control animal (right row) on the level of the motor cortex (M1), hippocampus (Hip), visual cortex (V1), cervical spinal cord (SC-C), and thoracic spinal cord (SC-T) after $6 \mathrm{~d}$ of pump infusion. Scale bar for M1, V1, and Hip represents $3 \mathrm{~mm}$; scale bar for spinal cord regions represents $0.5 \mathrm{~mm}$. ROD, Relative optical density as a measurement for staining intensity of the anti-Nogo-A Ab. Equal exposure for densitometry for all the sections. E, Levels of the anti-Nogo-A Ab in M1, V1, Hip, SC-C, and SC-T shown by Western blot protein detection after $6 \mathrm{~d}$ of Ab infusion compared with noninfused control animals. H-chain, Heavy chain; L-chain, light chain. $\boldsymbol{F}$, Titration of pure anti-Nogo-A Ab at 50, 25, and $12.5 \mathrm{ng} /$ lane compared with Ab levels in Hip, V1, and M1 after $6 \mathrm{~d}$ of Ab infusion and in control animals.

than both control groups toward the end of the first $2 \mathrm{~d}$. From day 3 on, anti-Nogo-A-treated rats started their training sessions with higher success rates, suggesting advanced memory consolidation, and maintained elevated scores throughout all phases of the subsequent daily sessions compared with the control groups. Another form of assessing skilled movement acquisition is to measure the degree of precision and fine tuning of the learned movement. To determine this component, we analyzed exclusively first attempts of successfully grasped pellets in a randomly selected subset of the three experimental groups. To be counted as a positive first attempt, the rat had to grasp the pellet in a single monolithic movement execution without disruption, hesitation, or repetition of the individual motion components. Anti-NogoA-treated animals achieved significantly higher successful first attempt values on days 3-6 compared with control-Ab-treated rats (day 3 anti-Nogo-A: $11.3 \pm 1.7 \%$, control IgG Ab: $6.8 \pm$ $0.8 \%$, sham: $8.7 \pm 0.7 \%$; day 4 anti-Nogo-A: $17.4 \pm 1.8 \%$, control IgG Ab: $9.5 \pm 1.4 \%$, sham: $11.2 \pm 0.9 \%$; day 5 anti-Nogo-A: $16.2 \pm 2.0 \%$, control IgG Ab: $7.9 \pm 1.3 \%$, sham: $10.7 \pm 0.8 \%$; day 6 anti-Nogo-A: $14.5 \pm 1.6 \%$, control IgG Ab: $9.0 \pm 1.1 \%$, sham: 
$10.3 \pm 0.8 \% ; p=0.0089 ; 2$-way mixed ANOVA, between-subjects; significance obtained for days 3-6, $p<0.05$; Fig. $5 D$ ).

In summary, acute neutralization of Nogo-A with function blocking Abs improved the acquisition of a skilled motor task. These results demonstrate a novel role for Nogo-A in regulating motor skill learning.

\section{Anti-Nogo-A Ab treatment modulates spine density upon motor learning in rats}

Finally, we investigated whether the acute blockade of Nogo-A influences learning-dependent structural plasticity of dendritic spines in the rat motor cortex. Rats trained as described in the paragraph "Motor skill learning" and were killed $24 \mathrm{~h}$ after their last pellet-grasping session. Brain slices were prepared as for electrophysiology, fixed in 4\% PFA, labeled with DiI-coated particles using a gene gun (O'Brien and Lummis, 2007; Rauskolb et al., 2010), and incubated for $3 \mathrm{~d}$ to allow time for dye diffusion. The density of dendritic spines was determined for dendrites of layer $2 / 3$ pyramidal cells. Dendritic spine density was significantly higher in apical dendrites of the trained versus the untrained hemisphere of untreated control rats (sham untrained: $1.41 \pm$ $0.05, n=14$; trained: $1.59 \pm 0.04, n=13 ; p=0.01, \mathrm{df}=25, t$ test; Fig. $6 A, B, E)$. In rats receiving control IgG Abs, a similar increase in spine density was observed for the trained $\mathrm{HS}$ (control $\mathrm{Ab}$ untrained: $1.45 \pm 0.07, n=6$; control Ab trained: $1.65 \pm 0.06$, $n=12 ; p=0.05, \mathrm{df}=16, t$ test; Fig. $6 F)$. In the anti-Nogo-Atreated rats, spine density in the untrained HS was significantly higher compared to the untrained HS of both control groups (anti-Nogo-A untrained HS: $1.64 \pm 0.05, n=20$; control Ab untrained: $1.45 \pm 0.07, n=6 ; p=0.04 ; \mathrm{df}=23$, $t$ test; Fig. $6 C, H$ ). However, no significant further increase was detectable on the trained side (anti-Nogo-A untrained HS: $1.64 \pm 0.05, n=20$; anti-Nogo-A trained HS: $1.72 \pm 0.05, n=15 ; p=0.23, \mathrm{df}=32$, $t$ test; Fig. $6 D, G)$.

In summary, spine density for the apical dendrites of layer $2 / 3$ pyramidal neurons was equally increased by both, anti-Nogo-A $\mathrm{Ab}$ treatment and training. The combination of anti-Nogo- $\mathrm{A} \mathrm{Ab}$ treatment and training-driven plasticity resulted in indistinguishable spine density levels between trained and untrained hemispheres of the same animals.

\section{Tissue penetration and distribution of CSF transported anti- Nogo-A Abs after intrathecal administration}

Anti-Nogo-A Abs were continuously infused for $6 \mathrm{~d}$ into the subdural space over the thoracic spinal cord by an osmotic minipump. Very high levels of anti-Nogo-A Abs were detected in the spinal cord tissue close to the inlet by immunohistochemistry and Western blotting (Fig. $7 D-F$ ). In the brain, the mouse antiNogo-A Abs showed a gradient of penetration from the outer CSF spaces into the tissue. Abs were clearly detectable in the motor cortex, visual cortex, and hippocampus (Fig. $7 A, B, D-F$ ) of spinally infused animals. Cellular uptake of the anti-Nogo-A $\mathrm{Ab}$ was observed in layer $2 / 3$ cells of the motor cortex (Fig. $7 B$ ).

These experiments show that spinal intrathecal infusion of monoclonal Abs against Nogo-A lead to a distribution of the $\mathrm{Ab}$ through the CSF circulation and penetration into brain and spinal cord tissue in adult rodents.

\section{Discussion}

We tested the effects of Nogo-A neutralization on synaptic plasticity in the motor cortex and on motor learning in the uninjured mature CNS. Blockade of Nogo signaling enhanced synaptic strength and increased spine formation and density. These find- ings were correlated with improved motor skill learning in vivo upon blockade of Nogo-A function. The identification of Nogo-A as an influential factor for activity-dependent synaptic plasticity and learning suggests novel roles for the protein beyond its known function in growth inhibition and regulation of neuronal morphology. This concept is consistent with recent results showing that blockade or ablation of Nogo-A or NgR1 increases structural and functional synaptic plasticity in the hippocampus, somatosensory cortex, and cerebellum (Lee et al., 2008; Raiker et al., 2010; Zagrebelsky et al., 2010; Delekate et al., 2011; Wills et al., 2012; Akbik et al., 2013; Petrinovic et al., 2013; Tews et al., 2013).

We induced LTP and LTD multiple times in the same pathway in the motor cortex to determine whether the limits of the synaptic modification range are influenced by Nogo signaling. We found that interference with Nogo-A signaling leads to enhancement of LTP saturation without altering maximal LTD. This change expands the dynamic range within which synapses operate. Enlargement of the synaptic range has been correlated with learning in vivo, possibly through a larger learning capacity per synapse (Bienenstock et al., 1982; Kirkwood et al., 1996; RioultPedotti et al., 2000; Martin and Morris, 2001; Bear, 2003; Savić et al., 2003; Rioult-Pedotti et al., 2007; Holtmaat and Svoboda, 2009). Our results identify Nogo-A as a molecule that permits control of synaptic range modifications and of learning in vivo. The effects in the slice preparations were visible within minutes after the anti-Nogo-A Ab application, supporting a local effect of neuronal Nogo-A in the presynaptic and/or postsynaptic membrane. NgR1 was also present in synaptic and extrasynaptic membranes of both compartments in the motor cortex.

\section{Nogo-A-mediated changes in structural synaptic plasticity}

Long-term changes in synaptic efficacy turn into changes in synapse structure and number as shown for layers $2 / 3$ and 5 motor cortex neurons (Kleim et al., 1996; Kleim et al., 2002; Yu and Zuo, 2011). Newly formed spines are mostly transient, but can be stabilized by learning (Holtmaat et al., 2005; Holtmaat et al., 2006; Hofer et al., 2009; Xu et al., 2009). Several classes of molecules, including neurotrophic factors, adhesion molecules, and axonal guidance molecules, were shown to influence LTP/LTD and stability of synapses (Klein, 2009; Dityatev et al., 2010; Park and Poo, 2012; Mironova and Giger, 2013). Nogo-A, a well known growth inhibitory protein (Schwab, 2010), and its receptor, NgR1, now join the family of synaptic plasticity regulators. Interference with Nogo-A signaling leads to increased spine formation and more immature spine phenotypes, suggesting that the Nogo system is required for spine stabilization (Lee et al., 2008; Pradhan et al., 2010; Zagrebelsky et al., 2010; Wills et al., 2012; Mironova and Giger, 2013).

Although treatment with anti-Nogo-A led to increased spine density of the untrained hemisphere compared with controls, no further elevation of the spine density was observed in the trained hemisphere, indicating a possible saturation or ceiling effect.

\section{Nogo-A affects motor learning in vivo}

Because LTP and LTD have been suggested as cellular correlates for learning and memory and improvement of the learned motor skill is accompanied by changes in synaptic strength (RioultPedotti et al., 1998; Rioult-Pedotti et al., 2000), synaptic number and shape (Xu et al., 2009; Fu and Zuo, 2011; Yu and Zuo, 2011; Fu et al., 2012), and the synaptic modification range (RioultPedotti et al., 2000; Rioult-Pedotti et al., 2007), we hypothesized that anti-Nogo-A-mediated enhancement of structural and functional synaptic plasticity enlarges the memory capacity per synapse, leading to improved motor learning in vivo. Our results 
support this hypothesis and identify Nogo-A as a molecule that regulates synaptic plasticity and motor learning.

In summary, functional blockade of Nogo-A and NgR1, which are present at synaptic sites in the motor cortex, enhances synaptic gain and capacity through strengthening of connections, the formation of new synapses, and an overall increase of the synaptic modification range in the motor cortex of adult rodents. These changes are accompanied by improvement of motor skill learning in vivo upon treatment with function-blocking antiNogo-A Abs. The relevance of this mechanism for functional recovery and rehabilitation after CNS injury remains to be investigated.

\section{References}

Akbik F, Cafferty WB, Strittmatter SM (2012) Myelin associated inhibitors: a link between injury-induced and experience-dependent plasticity. Exp Neurol 235:43-52. CrossRef Medline

Akbik FV, Bhagat SM, Patel PR, Cafferty WB, Strittmatter SM (2013) Anatomical plasticity of adult brain is titrated by nogo receptor 1 . Neuron 77:859-866. CrossRef Medline

Aroniadou VA, Keller A (1995) Mechanisms of LTP induction in rat motor cortex in vitro. Cereb Cortex 5:353-362. CrossRef Medline

Bear MF (2003) Bidirectional synaptic plasticity: from theory to reality. Philos Trans R Soc Lond B Biol Sci 358:649-655. CrossRef Medline

Bienenstock EL, Cooper LN, Munro PW (1982) Theory for the development of neuron selectivity: orientation specificity and binocular interaction in visual cortex. J Neurosci 2:32-48. Medline

Buitrago MM, Schulz JB, Dichgans J, Luft AR (2004a) Short and long-term motor skill learning in an accelerated rotarod training paradigm. Neurobiol Learn Mem 81:211-216. CrossRef Medline

Buitrago MM, Ringer T, Schulz JB, Dichgans J, Luft AR (2004b) Characterization of motor skill and instrumental learning time scales in a skilled reaching task in rat. Behav Brain Res 155:249-256. CrossRef Medline

Caroni P, Schwab ME (1988) Antibody against myelin-associated inhibitor of neurite growth neutralizes nonpermissive substrate properties of CNS white matter. Neuron 1:85-96. CrossRef Medline

Chen MS, Huber AB, van der Haar ME, Frank M, Schnell L, Spillmann AA, Christ F, Schwab ME (2000) Nogo-A is a myelin-associated neurite outgrowth inhibitor and an antigen for monoclonal antibody IN-1. Nature 403:434-439. CrossRef Medline

Cohen JD, Castro-Alamancos MA (2005) Skilled motor learning does not enhance long-term depression in the motor cortex in vivo. J Neurophysiol 93:1486-1497. CrossRef Medline

Craveiro LM, Hakkoum D, Weinmann O, Montani L, Stoppini L, Schwab ME (2008) Neutralization of the membrane protein Nogo-A enhances growth and reactive sprouting in established organotypic hippocampal slice cultures. Eur J Neurosci 28:1808-1824. CrossRef Medline

Delekate A, Zagrebelsky M, Kramer S, Schwab ME, Korte M (2011) NogoA restricts synaptic plasticity in the adult hippocampus on a fast time scale. Proc Natl Acad Sci U S A 108:2569-2574. CrossRef Medline

Dityatev A, Schachner M, Sonderegger P (2010) The dual role of the extracellular matrix in synaptic plasticity and homeostasis. Nat Rev Neurosci 11:735-746. CrossRef Medline

Donoghue JP, Wise SP (1982) The motor cortex of the rat: cytoarchitecture and microstimulation mapping. J Comp Neurol 212:76-88. CrossRef Medline

Feng G, Mellor RH, Bernstein M, Keller-Peck C, Nguyen QT, Wallace M, Nerbonne JM, Lichtman JW, Sanes JR (2000) Imaging neuronal subsets in transgenic mice expressing multiple spectral variants of GFP. Neuron 28:41-51. CrossRef Medline

Fournier AE, Takizawa BT, Strittmatter SM (2003) Rho kinase inhibition enhances axonal regeneration in the injured CNS. J Neurosci 23:14161423. Medline

Fritschy JM, Meskenaite V, Weinmann O, Honer M, Benke D, Mohler H (1999) GABAB-receptor splice variants GB1a and GB1b in rat brain: developmental regulation, cellular distribution and extrasynaptic localization. Eur J Neurosci 11:761-768. CrossRef Medline

Fu M, Zuo Y (2011) Experience-dependent structural plasticity in the cortex. Trends Neurosci 34:177-187. CrossRef Medline

Fu M, Yu X, Lu J, Zuo Y (2012) Repetitive motor learning induces coordi- nated formation of clustered dendritic spines in vivo. Nature 483:92-95. CrossRef Medline

Gonzenbach RR, Schwab ME (2008) Disinhibition of neurite growth to repair the injured adult CNS: focusing on Nogo. Cell Mol Life Sci 65:161176. CrossRef Medline

GrandPré T, Li S, Strittmatter SM (2002) Nogo-66 receptor antagonist peptide promotes axonal regeneration. Nature 417:547-551. CrossRef Medline

Grunwald IC, Korte M, Adelmann G, Plueck A, Kullander K, Adams RH, Frotscher M, Bonhoeffer T, Klein R (2004) Hippocampal plasticity requires postsynaptic ephrinBs. Nat Neurosci 7:33-40. CrossRef Medline

Harms KJ, Rioult-Pedotti MS, Carter DR, Dunaevsky A (2008) Transient spine expansion and learning-induced plasticity in layer 1 primary motor cortex. J Neurosci 28:5686-5690. CrossRef Medline

Hess G, Donoghue JP (1996) Long-term depression of horizontal connections in rat motor cortex. Eur J Neurosci 8:658-665. CrossRef Medline

Hess G, Aizenman CD, Donoghue JP (1996) Conditions for the induction of long-term potentiation in layer II/III horizontal connections of the rat motor cortex. J Neurophysiol 75:1765-1778. Medline

Hofer SB, Mrsic-Flogel TD, Bonhoeffer T, Hübener M (2009) Experience leaves a lasting structural trace in cortical circuits. Nature 457:313-317. CrossRef Medline

Holtmaat A, Svoboda K (2009) Experience-dependent structural synaptic plasticity in the mammalian brain. Nat Rev Neurosci 10:647-658. CrossRef Medline

Holtmaat AJ, Trachtenberg JT, Wilbrecht L, Shepherd GM, Zhang X, Knott GW, Svoboda K (2005) Transient and persistent dendritic spines in the neocortex in vivo. Neuron 45:279-291. CrossRef Medline

Holtmaat A, Wilbrecht L, Knott GW, Welker E, Svoboda K (2006) Experience-dependent and cell-type-specific spine growth in the neocortex. Nature 441:979-983. CrossRef Medline

Huber AB, Weinmann O, Brösamle C, Oertle T, Schwab ME (2002) Patterns of Nogo mRNA and protein expression in the developing and adult rat and after CNS lesions. J Neurosci 22:3553-3567. Medline

Ito M (2001) Cerebellar long-term depression: characterization, signal transduction, and functional roles. Physiol Rev 81:1143-1195. Medline

Jin WL, Liu YY, Liu HL, Yang H, Wang Y, Jiao XY, Ju G (2003) Intraneuronal localization of Nogo-A in the rat. J Comp Neurol 458:1-10. CrossRef Medline

Josephson A, Widenfalk J, Widmer HW, Olson L, Spenger C (2001) NOGO mRNA expression in adult and fetal human and rat nervous tissue and in weight drop injury. Exp Neurol 169:319-328. CrossRef Medline

Kandel ER (2001) The molecular biology of memory storage: a dialogue between genes and synapses. Science 294:1030-1038. CrossRef Medline

Karni A, Meyer G, Rey-Hipolito C, Jezzard P, Adams MM, Turner R, Ungerleider LG (1998) The acquisition of skilled motor performance: fast and slow experience-driven changes in primary motor cortex. Proc Natl Acad Sci U S A 95:861-868. CrossRef Medline

Kempf A, Tews B, Arzt ME, Weinmann O, Obermair FJ, Pernet V, Zagrebelsky M, Delekate A, Iobbi C, Zemmar A, Ristic Z, Gullo M, Spies P, Dodd D, Gygax D, Korte M, Schwab ME (2014) The sphingolipid receptor S1PR2 is a receptor for Nogo-a repressing synaptic plasticity. PLoS Biol 12:e1001763. CrossRef Medline

Kim JE, Liu BP, Park JH, Strittmatter SM (2004) Nogo-66 receptor prevents raphespinal and rubrospinal axon regeneration and limits functional recovery from spinal cord injury. Neuron 44:439-451. CrossRef Medline

Kirkwood A, Rioult MC, Bear MF (1996) Experience-dependent modification of synaptic plasticity in visual cortex. Nature 381:526-528. CrossRef Medline

Kleim JA, Lussnig E, Schwarz ER, Comery TA, Greenough WT (1996) Synaptogenesis and Fos expression in the motor cortex of the adult rat after motor skill learning. J Neurosci 16:4529-4535. Medline

Kleim JA, Barbay S, Cooper NR, Hogg TM, Reidel CN, Remple MS, Nudo RJ (2002) Motor learning-dependent synaptogenesis is localized to functionally reorganized motor cortex. Neurobiol Learn Mem 77:63-77. CrossRef Medline

Klein R (2009) Bidirectional modulation of synaptic functions by Eph/ephrin signaling. Nat Neurosci 12:15-20. CrossRef Medline

Lee H, Raiker SJ, Venkatesh K, Geary R, Robak LA, Zhang Y, Yeh HH, Shrager P, Giger RJ (2008) Synaptic function for the Nogo-66 receptor NgR1: regulation of dendritic spine morphology and activity-dependent synaptic strength. J Neurosci 28:2753-2765. CrossRef Medline 
Liebscher T, Schnell L, Schnell D, Scholl J, Schneider R, Gullo M, Fouad K, Mir A, Rausch M, Kindler D, Hamers FP, Schwab ME (2005) Nogo-A antibody improves regeneration and locomotion of spinal cord-injured rats. Ann Neurol 58:706-719. CrossRef Medline

Llinás RR (2011) Cerebellar motor learning versus cerebellar motor timing: the climbing fibre story. J Physiol 589:3423-3432. CrossRef Medline

Maier IC, Ichiyama RM, Courtine G, Schnell L, Lavrov I, Edgerton VR, Schwab ME (2009) Differential effects of anti-Nogo-A antibody treatment and treadmill training in rats with incomplete spinal cord injury. Brain 132:1426-1440. CrossRef Medline

Marr D (1969) A theory of cerebellar cortex. J Physiol 202:437-470. Medline

Martin SJ, Morris RG (2001) Cortical plasticity: it's all the range! Curr Biol R57-R59. CrossRef Medline

McGee AW, Yang Y, Fischer QS, Daw NW, Strittmatter SM (2005) Experience-driven plasticity of visual cortex limited by myelin and Nogo receptor. Science 309:2222-2226. CrossRef Medline

Mironova YA, Giger RJ (2013) Where no synapses go: gatekeepers of circuit remodeling and synaptic strength. Trends Neurosci 36:363-373. CrossRef Medline

Morris RG, Anderson E, Lynch GS, Baudry M (1986) Selective impairment of learning and blockade of long-term potentiation by an N-methyl-Daspartate receptor antagonist, AP5. Nature 319:774-776. CrossRef Medline

O'Brien JA, Lummis SC (2007) Diolistics: incorporating fluorescent dyes into biological samples using a gene gun. Trends Biotechnol 25:530-534. CrossRef Medline

Oertle T, van der Haar ME, Bandtlow CE, Robeva A, Burfeind P, Buss A, Huber AB, Simonen M, Schnell L, Brösamle C, Kaupmann K, Vallon R, Schwab ME (2003) Nogo-A inhibits neurite outgrowth and cell spreading with three discrete regions. J Neurosci 23:5393-5406. Medline

Park H, Poo MM (2012) Neurotrophin regulation of neural circuit development and function. Nat Rev Neurosci 14:7-23. CrossRef Medline

Petrinovic MM, Hourez R, Aloy EM, Dewarrat G, Gall D, Weinmann O, Gaudias J, Bachmann LC, Schiffmann SN, Vogt KE, Schwab ME (2013) Neuronal Nogo-A negatively regulates dendritic morphology and synaptic transmission in the cerebellum. Proc Natl Acad Sci U S A 110:10831088. CrossRef Medline

Pradhan AD, Case AM, Farrer RG, Tsai SY, Cheatwood JL, Martin JL, Kartje GL (2010) Dendritic spine alterations in neocortical pyramidal neurons following postnatal neuronal Nogo-A knockdown. Dev Neurosci 32:313320. CrossRef Medline

Raiker SJ, Lee H, Baldwin KT, Duan Y, Shrager P, Giger RJ (2010) Oligodendrocyte-myelin glycoprotein and Nogo negatively regulate activity-dependent synaptic plasticity. J Neurosci 30:12432-12445. CrossRef Medline

Rauskolb S, Zagrebelsky M, Dreznjak A, Deogracias R, Matsumoto T, Wiese S, Erne B, Sendtner M, Schaeren-Wiemers N, Korte M, Barde YA (2010) Global deprivation of brain-derived neurotrophic factor in the CNS reveals an area-specific requirement for dendritic growth. J Neurosci 30: 1739-1749. CrossRef Medline

Rioult-Pedotti MS, Friedman D, Hess G, Donoghue JP (1998) Strengthening of horizontal cortical connections following skill learning. Nat Neurosci 1:230-234. CrossRef Medline

Rioult-Pedotti MS, Friedman D, Donoghue JP (2000) Learning-induced LTP in neocortex. Science 290:533-536. CrossRef Medline

Rioult-Pedotti MS, Donoghue JP, Dunaevsky A (2007) Plasticity of the synaptic modification range. J Neurophysiol 98:3688-3695. CrossRef Medline

Rolando C, Parolisi R, Boda E, Schwab ME, Rossi F, Buffo A (2012) Distinct roles of Nogo-a and Nogo receptor 1 in the homeostatic regulation of adult neural stem cell function and neuroblast migration. J Neurosci 32: 17788-17799. CrossRef Medline

Savić N, Lüthi A, Gähwiler BH, McKinney RA (2003) N-methyl-Daspartate receptor blockade during development lowers long-term potentiation threshold without affecting dynamic range of CA3-CA1 synapses. Proc Natl Acad Sci U S A 100:5503-5508. CrossRef Medline

Schmued LC (1990) A rapid, sensitive histochemical stain for myelin in frozen brain sections. J Histochem Cytochem 38:717-720. CrossRef Medline

Schmued L, Bowyer J, Cozart M, Heard D, Binienda Z, Paule M (2008) Introducing Black-Gold II, a highly soluble gold phosphate complex with several unique advantages for the histochemical localization of myelin. Brain Res 1229:210-217. CrossRef Medline

Schnell L, Schwab ME (1990) Axonal regeneration in the rat spinal cord produced by an antibody against myelin-associated neurite growth inhibitors. Nature 343:269-272. CrossRef Medline

Schulz PE, Cook EP, Johnston D (1994) Changes in paired-pulse facilitation suggest presynaptic involvement in long-term potentiation. J Neurosci 14:5325-5337. Medline

Schwab ME (2010) Functions of Nogo proteins and their receptors in the nervous system. Nat Rev Neurosci 11:799-811. CrossRef Medline

Syken J, Grandpre T, Kanold PO, Shatz CJ (2006) PirB restricts oculardominance plasticity in visual cortex. Science 313:1795-1800. CrossRef Medline

Tews B, Schonig K, Arzt ME, Clementi S, Rioult-Pedotti MS, Zemmar A, Berger SM, Schneider M, Enkel T, Weinmann O, Kasper H, Schwab ME, Bartsch D (2013) Synthetic microRNA-mediated downregulation of Nogo-A in transgenic rats reveals its role as regulator of synaptic plasticity and cognitive function. Proc Natl Acad Sci U S A. 110:6583-6588. CrossRef Medline

Wang X, Chun SJ, Treloar H, Vartanian T, Greer CA, Strittmatter SM (2002) Localization of Nogo-A and Nogo-66 receptor proteins at sites of axonmyelin and synaptic contact. J Neurosci 22:5505-5515. Medline

Weinmann O, Schnell L, Ghosh A, Montani L, Wiessner C, Wannier T, Rouiller E, Mir A, Schwab ME (2006) Intrathecally infused antibodies against Nogo-A penetrate the CNS and downregulate the endogenous neurite growth inhibitor Nogo-A. Mol Cell Neurosci 32:161-173. CrossRef Medline

Welsh JP, Yamaguchi H, Zeng XH, Kojo M, Nakada Y, Takagi A, Sugimori M, Llinás RR (2005) Normal motor learning during pharmacological prevention of Purkinje cell long-term depression. Proc Natl Acad Sci U S A 102:17166-17171. CrossRef Medline

Whitlock JR, Heynen AJ, Shuler MG, Bear MF (2006) Learning induces long-term potentiation in the hippocampus. Science 313:1093-1097. CrossRef Medline

Willi R, Weinmann O, Winter C, Klein J, Sohr R, Schnell L, Yee BK, Feldon J, Schwab ME (2010) Constitutive genetic deletion of the growth regulator Nogo-A induces schizophrenia-related endophenotypes. J Neurosci 30: 556-567. CrossRef Medline

Wills ZP, Mandel-Brehm C, Mardinly AR, McCord AE, Giger RJ, Greenberg ME (2012) The nogo receptor family restricts synapse number in the developing hippocampus. Neuron 73:466-481. CrossRef Medline

Xu T, Yu X, Perlik AJ, Tobin WF, Zweig JA, Tennant K, Jones T, Zuo Y (2009) Rapid formation and selective stabilization of synapses for enduring motor memories. Nature 462:915-919. CrossRef Medline

Yang G, Pan F, Gan WB (2009) Stably maintained dendritic spines are associated with lifelong memories. Nature 462:920-924. CrossRef Medline

Yu X, Zuo Y (2011) Spine plasticity in the motor cortex. Curr Opin Neurobiol 21:169-174. CrossRef Medline

Zagrebelsky M, Schweigreiter R, Bandtlow CE, Schwab ME, Korte M (2010) Nogo-A stabilizes the architecture of hippocampal neurons. J Neurosci 30:13220-13234. CrossRef Medline 